\title{
Adolescent sexual and reproductive health situation: Insights from the 2014 Kenya Demographic and Health Survey
}

\author{
Francis Obare \\ Population Council \\ George Odwe \\ Harriet Birungi \\ Population Council
}

Follow this and additional works at: https://knowledgecommons.popcouncil.org/departments_sbsr-rh

Part of the Demography, Population, and Ecology Commons, Family, Life Course, and Society Commons, Gender and Sexuality Commons, International Public Health Commons, Maternal and Child Health Commons, and the Women's Health Commons How does access to this work benefit you? Let us know!

\section{Recommended Citation}

Obare, Francis, George Odwe, and Harriet Birungi. 2016. "Adolescent sexual and reproductive health situation: Insights from the 2014 Kenya Demographic and Health Survey," STEP UP Research Report. Nairobi: Population Council. 


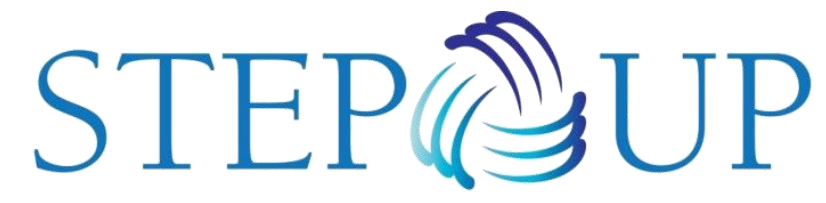

STRENGTHENING EVIDENCE FOR PROGRAMMING ON UNINTENDED PREGNANCY
KENYA

RESEARCH REPORT

APRIL 2016

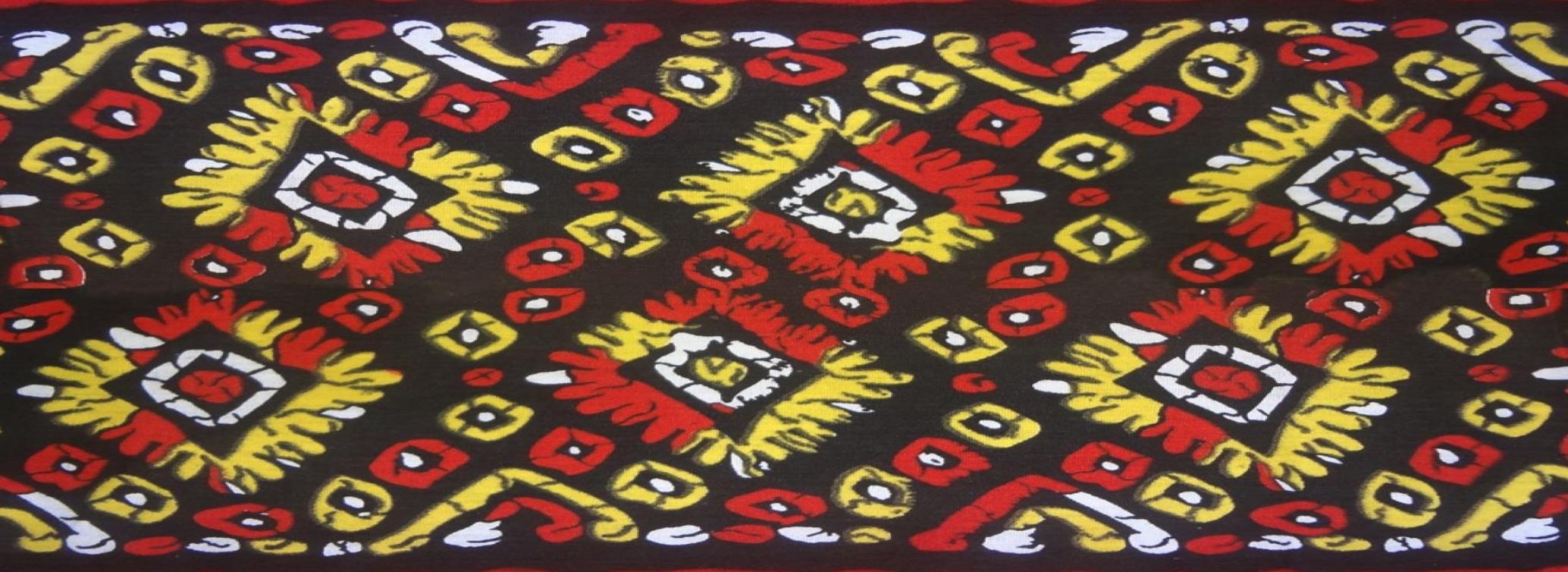

Adolescent Sexual and Reproductive Health Situation: Insights from the 2014 Kenya Demographic and Health Survey

FRANCIS OBARE, GEORGE ODWE AND HARRIET BIRUNGI

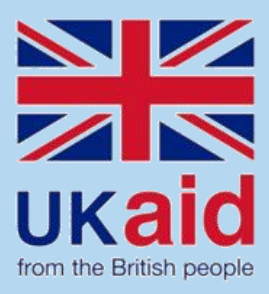


The STEP UP (Strengthening Evidence for Programming on Unintended Pregnancy) Research Programme Consortium generates policy-relevant research to promote an evidence-based approach for improving access to family planning and safe abortion. STEP UP focuses its activities in five countries: Bangladesh, Ghana, India, Kenya, and Senegal. STEP UP is coordinated by the Population Council in partnership with the African Population and Health Research Center; The International Center for Diarrhoeal Disease Research Bangladesh (icddr-b), the London School of Hygiene and Tropical Medicine; Marie Stopes International; and Partners in Population and Development. STEP UP is funded by UK aid from the UK Government.

www.stepup.popcouncil.org

\section{POPULATION COUNCIL \\ Ideas. Evidence. Impact.}

The Population Council confronts critical health and development issues-from stopping the spread of HIV to improving reproductive health and ensuring that young people lead full and productive lives. Through biomedical, social science, and public health research in 50 countries, we work with our partners to deliver solutions that lead to more effective policies, programs, and technologies that improve lives around the world. Established in 1952 and headquartered in New York, the Council is a non-governmental, non-profit organization governed by an international board of trustees.

www.popcouncil.org

Suggested citation: Obare, Francis, George Odwe and Harriet Birungi. 2016. "Adolescent Sexual and Reproductive Health Situation in Kenya: Insights from the 2014 Kenya Demographic and Health Survey." STEP UP Research Programme Research Consortium. Nairobi: Population Council.

(C) 2016 Population Council 


\section{Acknowledgements}

The analysis was supported by UKaid from the Department for International Development (DFID) through the STEP UP (Strengthening Evidence for Programming on Unintended Pregnancy) Research Programme Consortium. The data used are publicly available from the MEASURE DHS program at ICF International (http://dhsprogram.com/). The DHS program is funded by the United States Agency for International Development (USAID) for population and health surveys in developing countries. The 2014 Kenya Demographic and Health Survey was funded by the Government of Kenya with support from USAID, United Nations Population Fund (UNFPA), DFID, World Bank, Danish Development Agency (DANIDA), United Nations Children's Fund (UNICEF), German Development Bank (KfW), Clinton Health Access Initiative (CHAl), World Food Programme (WFP), and Micronutrient Initiative (MI). The survey was implemented by the Kenya National Bureau of Statistics (KNBS) in collaboration with the Ministry of Health, the National AIDS Control Council (NACC), the National Council for Population and Development (NCPD), and the Kenya Medical Research Institute (KEMRI) while ICF International provided technical assistance. 


\section{Table of Contents}

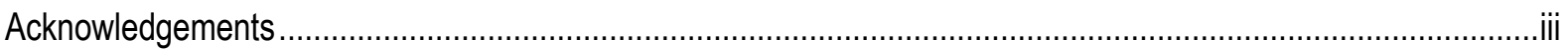

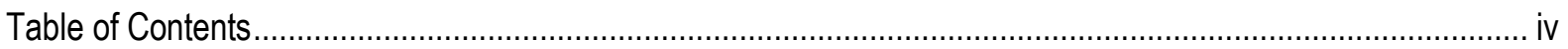

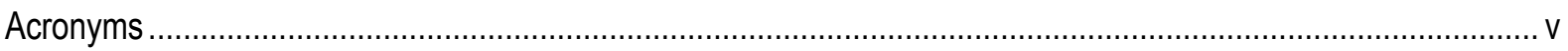

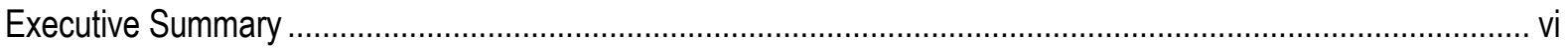

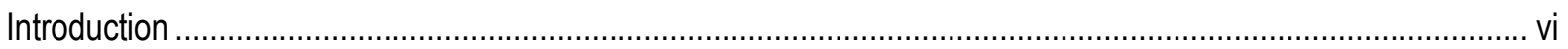

Key sexual and Reproductive Health Indicators................................................................................. vi

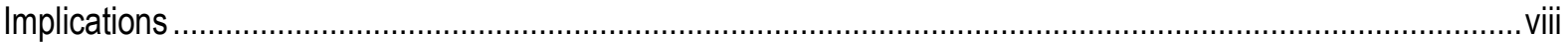

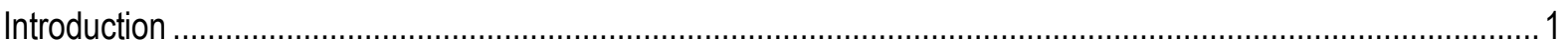

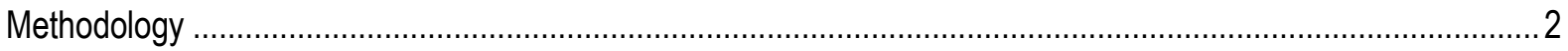

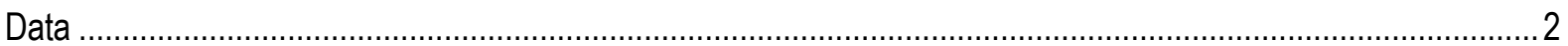

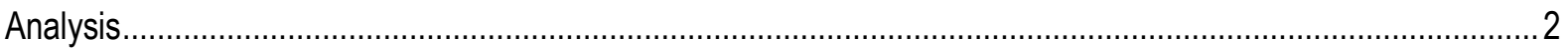

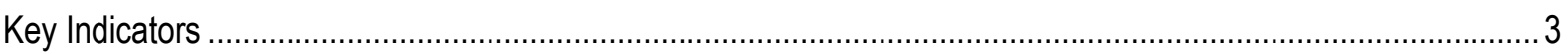

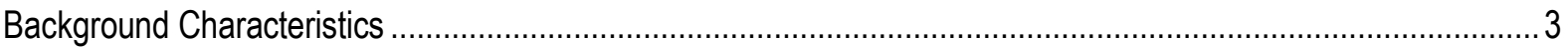

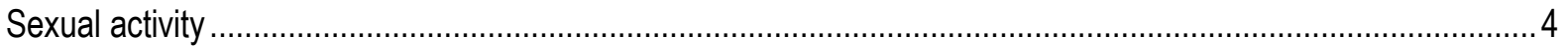

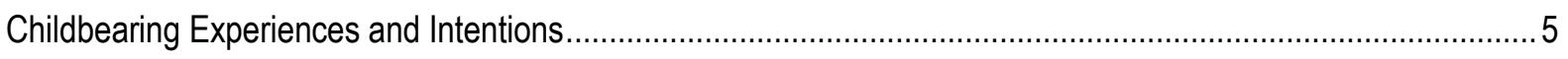

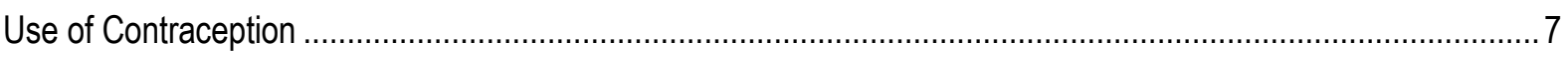

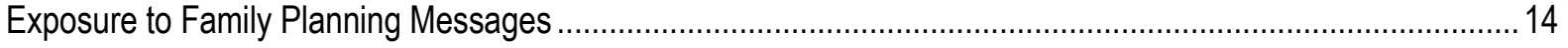

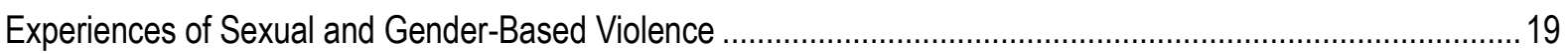

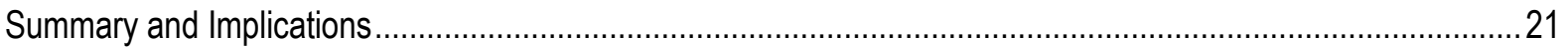

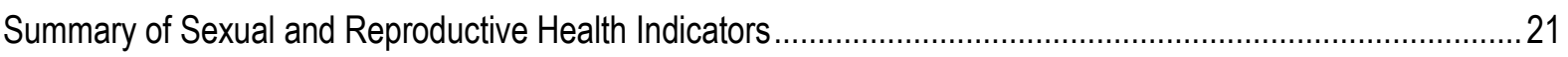

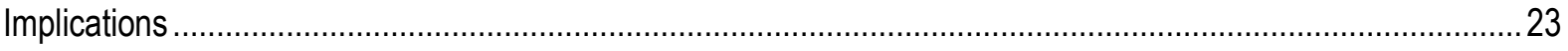

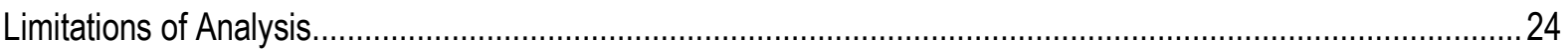

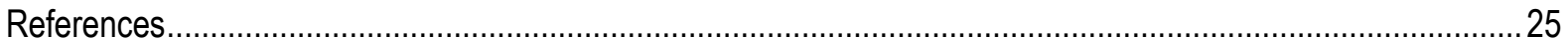

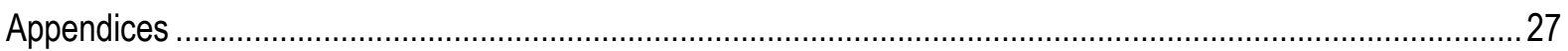




\section{Acronyms}

AIDS $\quad$ Acquired Immune Deficiency Syndrome

HIV Human Immunodeficiency Virus

ICPD International Conference on Population and Development

KDHS Kenya Demographic and Health Survey

KNBS Kenya National Bureau of Statistics

SRH Sexual and Reproductive Health

STI Sexually Transmitted Infection

UN/DPI United Nations Department of Public Information

UNFPA United Nations Population Fund

UNICEF United Nations Children's Fund

WHO World Health Organization 


\section{Executive Summary}

\section{Introduction}

Studies have documented poor sexual and reproductive health (SRH) outcomes among adolescents ages 10 to 19 in many developing countries. These poor outcomes are likely to be exacerbated in contexts such as subSaharan Africa, where the prevalence of teenage pregnancies are high, health care systems are weak, and even profound disparities in health outcomes exist in settings with relatively good health care services, such as urban areas. Addressing adolescent sexual and reproductive health needs therefore remains a priority for many governments in developing countries. The 2015 Kenya National Adolescent Sexual and Reproductive Health Policy, for instance, recognizes the importance of addressing adolescent sexual and reproductive health needs for achieving the country's development goals. Although estimates from the 2014 Kenya Demographic and Health Survey show the country registered improvements in key reproductive, maternal and child health outcomes, adolescent outcomes likely remain poor given the challenges associated with adequately addressing their sexual and reproductive health needs. This report presents findings of further analysis of the 2014 Kenya Demographic and Health Survey on key sexual and reproductive health outcomes among adolescent girls and boys 15 to 19 years old in Kenya. Understanding the sexual and reproductive health outcomes of adolescents is, in turn, important for identifying areas or sub-groups that need attention, and for the design of appropriate interventions.

\section{Key sexual and Reproductive Health Indicators}

- Compared to boys, a lower proportion of adolescent girls interviewed in 2014 attended school at any one time during the year $(68 \%$ and $78 \%$, respectively), while a higher proportion of girls than boys had ever been married ( $13 \%$ and $1 \%$, respectively). Although the proportion of adolescent girls and boys that attended school at any one time in 2014 was higher in rural than in urban areas, the proportion with secondary and higher educations was greater in urban than in rural areas. There were, however, no variations in the proportions of adolescent girls and boys that had ever been married, by type of place of residence (14\% and $13 \%$ of urban and rural adolescent girls, respectively, and $1 \%$ of urban and rural adolescent boys).

- More than one third (37\%) of adolescent girls and 41 percent of adolescent boys had ever had sexual intercourse, with sexual activity higher among urban than rural adolescents ( $41 \%$ and $35 \%$ of urban and rural adolescent girls, and $42 \%$ and $40 \%$ of urban and rural adolescent boys, respectively). Sexual activity was also higher among older adolescents (18 to 19 years old), those who did not attend school at any time in 2014, and girls with primary or less education. The proportion of adolescent girls who had ever had sexual intercourse ranged from 64 percent in West Pokot County to 15 percent in Nyandarua County.

- Eighteen percent of adolescent girls 15 to 19 years old had begun childbearing (i.e. had ever given birth or were pregnant at the time of the survey). Adolescent childbearing was higher in rural than in urban areas (19\% and $17 \%$, respectively), among 18 to 19 year olds, those with primary or no schooling, those who did not attend school at any time in 2014, ever married individuals, and those from households in the bottom two wealth quintiles, with the patterns consistent in both urban and rural areas. Adolescent childbearing also ranged from 40 percent in Narok County to seven percent in Nyeri County.

- More than one quarter (29\%) of adolescent girls who had begun childbearing reported ever experiencing unintended pregnancy, i.e. a previous birth or current pregnancy, either wanted later $(28.8 \%)$ or not at all $(0.2 \%)$, with the proportion greater in rural than in urban areas (30\% and $28 \%$, respectively) among 15 to 
17 year olds, those with secondary and higher educations, those who attended school at any time in 2014, and never married individuals.

- About one quarter (27\%) of adolescent girls and 44 percent of adolescent boys who had ever had sexual intercourse reported using any method of contraception at the time of the survey, with a large proportion ( $25 \%$ of girls and $43 \%$ of boys) using modern methods. Contraceptive use was higher among urban than rural adolescents, those 18 to 19 years old, and those who did not attend school at any time in 2014. Use of modern methods among sexually active adolescent girls ranged from 50 percent in Kiambu County-to none in Garissa and Mandera counties. The most commonly used methods by sexually active adolescent girls were injectables $(48 \%)$, condoms $(26 \%)$, and implants $(12 \%)$, although use of injectables was higher in rural than urban areas (53\% and $42 \%$, respectively) while use of condoms, implants and pills was higher in urban than in rural areas.

- Most adolescent girls using contraception (47\%) obtained the methods from public health facilities, while 25 percent obtained them from private health facilities, and 20 percent obtained them from other sources including shops, mobile clinics, community-based distributors, and friends or relatives. Public facilities were major sources for those ages 18 to 19, those with primary or no schooling, those who did not attend school at any time in 2014, married individuals, and those from the poorest households, while private facilities were major sources for those 15 to 17 years old, those with secondary and higher educations, and those from the richest households. A higher proportion of those in urban areas obtained methods from private rather than public facilities ( $40 \%$ and $34 \%$, respectively), while in rural areas a higher proportion obtained their methods from public rather than private facilities (56\% and $14 \%$, respectively). Unlike adolescent girls, only 32 percent of adolescent boys using condoms obtained them from a health facility (public or private), with 66 percent obtaining them from other sources.

- Unmet need for contraception was higher among married adolescent girls (23\%) than among all married women (18\%), more for spacing (22\%) than limiting births (1\%), unlike for all married women, for whom it was equally for spacing and limiting. In addition, unmet need was higher among those ages 18 to $19(25 \%)$, those with primary or no schooling (24\%), and those from the poorest households $(32 \%)$. It was also higher in rural than urban areas $(29 \%$ and $14 \%)$, with variations by age, education, and household wealth index. In urban areas, it was higher among those 15 to 17 years old, those with primary or no schooling, and those from the poorest households, while in rural areas it was higher among those 18 to 19 years old, those with secondary and higher educations, and those from households in the extreme and middle quintiles.

- Most (71\%) adolescent girls not currently using contraception intend to use a method in the future, with the majority (52\%) intending to use a modern method, while a substantial proportion (18\%) did not know the method they intend to use. The proportion that did not know the method they intend to use was higher among those ages 15 to 17, those who attended school at any time in 2014, and unmarried individuals. The proportions of non-users who intend to use a method in future were similar in both urban and rural areas ( $72 \%$ and $71 \%$, respectively), although the proportion that did not know the method they intend to use was higher in urban than rural areas (22\% and $16 \%$, respectively). The proportion of adolescent girls intending to use a modern method in the future ranged from 89 percent in Nandi County-to two percent in Wajir-and no non-users in Mandera County reported any intention to use a method in the future.

- Most adolescent girls obtained family planning information from radio (66\%), followed by print media including newspapers, magazines or informational materials (49\%), and television (39\%). The proportions that heard about family planning from health care workers, public forums, social media, phone or e-mail, or community leaders were much lower $(19 \%, 19 \%, 11 \%, 6 \%$ and $24 \%$, respectively). A higher proportion of adolescent girls in urban than in rural areas obtained family planning information from multiple sources; girls obtaining family planning information from various sources ranged, with two percent in Wajir to 88 
percent in Taita Taveta hearing family planning information on the radio, three percent in West Pokot to 88 percent in Mombasa from print media, and five percent in Samburu to 86 percent in Nairobi from television. Regardless of the source of information, there was a positive correlation between the proportion of adolescent girls accessing information and current use of a method, with counties where access to information was high generally associated with greater use of a method. Similar to girls, radio was the most common source of family planning information for boys, followed by television and print media $(71 \%, 39 \%$ and $27 \%$, respectively).

- About one fifth (19\%) of ever married adolescent girls asked about experiences of gender-based violence reported emotional abuse abused (humiliation, threats of harm, insults) by their husbands or partners ( $16 \%$ in urban and $20 \%$ in rural areas). Less than 10 percent of adolescent girls asked about gender-based violence had experienced sexual abuse, either being forced to have sexual intercourse or perform sexual acts against their wishes ( $9 \%$ in urban and $5 \%$ in rural areas). Only a small fraction (3\%) of adolescent boys asked about gender-based violence reported any sexual abuse ( $4 \%$ in urban and $2 \%$ in rural areas). Physical abuse was the most common gender-based violence among adolescents, with 71 percent of girls and 58 percent of boys indicating ever being slapped, kicked, dragged, threatened, arm-twisted, pushed, or choked. The proportion of adolescent girls reporting experiences of physical abuse was higher in urban than rural areas $(75 \%$ and $70 \%$, respectively), while the proportion of boys reporting such abuse was higher in rural than urban areas (59\% and $53 \%$, respectively).

\section{Implications}

- Low use of contraception among sexually active adolescents coupled with high unmet need among married adolescent girls, high intentions to use a method in future among non-users, and lack of knowledge of methods to use, among a substantial proportion of those who intend to use contraception, suggests the need for concerted efforts to reach this segment of the population with targeted information and services.

- Differences in certain sexual and reproductive health indicators by socio-demographic characteristics suggest the need for contraceptive information and services responsive to the needs of various groups of adolescents, especially those hard to reach including the poor, those with low levels of education, and those in rural or remote areas.

- Variations in the importance of various sources of contraceptive information and services suggest that different contexts require different strategies. The public sector is more important in rural areas than the private sector is; a mix of the public and private sector approaches might work in urban areas; while in both contexts, radio would be the most common medium for reaching adolescents with contraceptive information.

- Although subject to under-reporting, the fact that a selection of ever married adolescent girls reported emotional abuse by their spouses or partners, and that a selection of adolescents reported sexual abuse, indicate that SRH interventions should consider addressing intimate partner violence as well as sexual abuse among this segment of the population. 


\section{Introduction}

A number of studies and national surveys in parts of the developing world-such as the Demographic and Health Surveys-have documented poor sexual and reproductive health (SRH) outcomes among adolescents ages 10 to 19. These outcomes include increased risks of unintended pregnancy, unsafe abortion, miscarriage, pre-term delivery, low birth weight, neonatal mortality, and sexually transmitted infections (STIS) including HIV and AIDS. The poor reproductive health $(\mathrm{RH})$ outcomes among adolescents have been attributed to low use of contraception or methods to prevent STI/HIV infection, physiological immaturity, inadequate use of RH care services, and poor socio-economic conditions (Abou-Zahr and Wardlaw 2003, Alam 2000, Chen et al. 2007, Conde-Agudelo et al. 2005, Jolly et al. 2000, Magadi et al. 2003, 2007, Magadi 2006, Reynolds et al. 2006). Moreover, partly because of the cultural views of teenage sexuality and pregnancy, and weak health care systems, RH services in many parts of the developing world are, in most cases, not oriented for adequately meeting adolescents' needs (Katz and Naré 2002, Warenius et al. 2006, Wood and Jakes 2006).

The poor RH outcomes of adolescents are likely to be exacerbated in contexts such as sub-Saharan Africa, where the prevalence of teenage pregnancies are high, health care systems are weak, and even profound disparities in health outcomes exist in settings with relatively good health care services such as urban areas (Fotso 2006, Magadi et al. 2003, 2007, Zere et al. 2007). Poor outcomes are further likely to exert even a greater burden on the health care systems of many developing countries and result in cyclic patterns whereby services are heavily geared towards addressing the consequences rather than their causes. Addressing adolescent SRH needs therefore remains a priority for many governments in developing countries. In Kenya, for instance, the 2015 National Adolescent Sexual and Reproductive Health Policy recognizes the importance of addressing adolescent SRH needs for achieving the country's development goals (Republic of Kenya 2015). Although estimates from the 2014 Kenya Demographic and Health Survey (KDHS) show the country registered improvements in key reproductive, maternal, and child health outcomes (KNBS et al. 2015), outcomes for adolescents likely remain poor given the challenges associated with adequately addressing their SRH needs.

This report presents findings of further analysis of the $2014 \mathrm{KDHS}$ on key SRH outcomes among adolescent girls and boys aged 15 to 19 in Kenya. Understanding the SRH outcomes of adolescents is, in turn, important for identifying areas or sub-groups that need attention and for designing appropriate interventions. This is in line with a number of international pronouncements-such as the 1994 International Conference on Population and Development (ICPD) and the 1995 Fourth World Conference on women (UN/DPI 1995, United Nations 1996)_that emphasise a rights-based approach to $\mathrm{SRH}$ programming for adolescents that entails non-discrimination in access to SRH information and services as well as involving adolescents in the identification, design and implementation of SRH programs targeted at meeting their needs. The United Nations Fund for Population Activities (UNFPA) and the United Nations Children's Fund (UNICEF) further underscored the importance of these aspects in addressing young people's SRH and developmental needs (UNFPA 2007, UNICEF et al. 2002). The World Health Organization (WHO) also emphasised that for sexual health to be attained and maintained, the sexual rights of all persons must be respected, protected, and fulfilled (WHO 2005). 


\section{Methodology}

\section{Data}

This report is based on further analysis of the 2014 KDHS data. The 2014 KDHS was a nationally representative survey of women and men of reproductive age (15-49 and 15-54 years, respectively). A total of 31,079 women and 12,819 men were interviewed. Unlike previous surveys, the 2014 survey was designed to capture certain key indicators at the county level. For logistical purposes, some households were selected for the full questionnaires while others were selected for a short questionnaire aimed at capturing important county indicators. Of 39,679 households selected for the survey, interviews were completed in 36,430, a household response rate of 99 percent (KNBS et al. 2015). Slightly less than half (48\%) of households where interviews were completed involved the full questionnaire, and a total of 14,741 women were interviewed from these households, out of 15,317 eligible, a response rate of 96 percent (KNBS et al. 2015). The rest of the women interviewed $(16,338)$ were from households selected for the short questionnaire, with a response rate of 97 percent (out of 16,855 eligible). Men were interviewed from every second household selected for the full questionnaire, with 90 percent of those eligible successfully interviewed. Nineteen percent of all women $(5,820)$ and 21 percent of all men $(2,540)$ interviewed were between the ages of 15 and 19 , and these respondents constitute the sample for the analysis in this report.

Women who responded to the full questionnaire were asked about their background characteristics, fertility experiences and preferences, knowledge and use of family planning (FP), maternal and child health, marriage and sexuality, adult and maternal mortality, work status, husband's background characteristics, awareness and behaviors related to HIV and other sexually transmitted infections (STIs), domestic violence, female circumcision, and fistula. The short questionnaire excluded questions about fertility preferences, infant and child feeding practices, work status, husband characteristics, adult and maternal mortality, domestic violence, female circumcision, and fistula. The man's questionnaire, on the other hand, excluded questions about maternal and child health, adult and maternal mortality, as well as female circumcision and fistula. The domestic violence module was administered to either a woman or man from a sub-sample of households selected for the full questionnaire. Further details about the survey are available in KNBS et al. (2015).

\section{Analysis}

Analysis for this report focuses on sexual activity, childbearing experiences and intentions, contraceptive use, exposure to FP messages and experiences of sexual and gender-based violence among adolescent girls and boys 15 to 19 years old. The analysis entails cross-tabulations of these indicators by adolescents' background characteristics including age, education, school attendance in 2014, marital status or experience, and household wealth quintiles. The analysis is stratified by urban and rural residence, and for all sites combined. Indicators for adolescent girls are further presented by county, where sample sizes permit, with the overall estimate for each county and estimate for individuals from households in the bottom three wealth quintiles in the county. It was not possible to present county estimates for boys because of the small sample sizes. Residential and county-specific household wealth quintiles were generated for the analysis. All estimates are weighted. 


\section{Key Indicators}

\section{Background Characteristics}

Most adolescent girls and boys interviewed in the 2014 KDHS were between 15 and 17 years old ( $60 \%$ of the girls and a similar proportion of boys), had primary level educations (50\% of girls and $54 \%$ of boys), attended school at any time in 2014 ( $68 \%$ of girls and $78 \%$ of boys), had never been married ( $87 \%$ of girls and $99 \%$ of boys), and were from households in the top two wealth quintiles ( $50 \%$ of girls and $45 \%$ of boys; Table 1).

Although the proportion of adolescent girls with secondary and higher educations was slightly higher than that of boys ( $48 \%$ and $45 \%$, respectively), a higher proportion of boys than girls attended school at any one time in 2014 ( $78 \%$ and $68 \%$, respectively). By contrast, a higher proportion of girls than boys had ever been married (13\% and $1 \%$, respectively).

Table 1: Distribution of adolescent girls and boys 15 to 19 years old, by background characteristics

\begin{tabular}{|c|c|c|c|c|c|c|}
\hline \multirow[b]{2}{*}{ Characteristics } & \multicolumn{2}{|c|}{ Urban } & \multicolumn{2}{|c|}{ Rural } & \multicolumn{2}{|c|}{ All sites } \\
\hline & $\begin{array}{c}\text { Female } \\
(\%)\end{array}$ & $\begin{array}{l}\text { Male } \\
(\%)\end{array}$ & $\begin{array}{c}\text { Female } \\
(\%)\end{array}$ & $\begin{array}{c}\text { Male } \\
(\%)\end{array}$ & $\begin{array}{c}\text { Female } \\
(\%)\end{array}$ & $\begin{array}{c}\text { Male } \\
(\%)\end{array}$ \\
\hline \multicolumn{7}{|l|}{ Age group (years) } \\
\hline $15-17$ & 52.4 & 54.2 & 64.0 & 62.6 & 60.3 & 60.3 \\
\hline $18-19$ & 47.6 & 45.8 & 36.0 & 37.4 & 39.7 & 39.7 \\
\hline \multicolumn{7}{|l|}{ Highest level of education } \\
\hline No schooling & 1.5 & 0.8 & 2.7 & 1.3 & 2.3 & 1.2 \\
\hline Primary & 37.6 & 40.8 & 55.7 & 58.5 & 49.9 & 53.5 \\
\hline Secondary and above & 60.9 & 58.4 & 41.7 & 40.2 & 47.8 & 45.3 \\
\hline \multicolumn{7}{|l|}{ Attended school at any time in 2014} \\
\hline No & 43.5 & 27.9 & 25.2 & 19.1 & 31.1 & 21.6 \\
\hline Yes & 55.5 & 72.0 & 74.2 & 80.4 & 68.3 & 78.1 \\
\hline Missing & 1.0 & 0.1 & 0.6 & 0.5 & 0.7 & 0.4 \\
\hline \multicolumn{7}{|l|}{ Marital experience } \\
\hline Never married & 85.6 & 99.4 & 87.4 & 99.2 & 86.8 & 99.3 \\
\hline Currently married/living together & 12.8 & 0.3 & 11.5 & 0.7 & 11.9 & 0.6 \\
\hline Formerly marrieda & 1.6 & 0.3 & 1.1 & 0.1 & 1.3 & 0.1 \\
\hline \multicolumn{7}{|l|}{ Household wealth quintile } \\
\hline Lowest & 13.4 & 17.2 & 9.6 & 8.3 & 10.8 & 10.8 \\
\hline Second & 14.9 & 22.1 & 19.7 & 20.1 & 18.2 & 20.6 \\
\hline Middle & 17.2 & 20.8 & 23.7 & 24.3 & 21.6 & 23.4 \\
\hline Fourth & 20.9 & 19.6 & 25.7 & 24.5 & 24.2 & 23.1 \\
\hline Highest & 33.8 & 20.3 & 21.3 & 22.7 & 25.3 & 22.1 \\
\hline All respondents & 100.0 & 100.0 & 100.0 & 100.0 & 100.0 & 100.0 \\
\hline Number of respondents & 1,859 & 709 & 3,961 & 1,831 & 5,820 & 2,540 \\
\hline
\end{tabular}

Certain characteristics of adolescents varied by place of residence. The proportion of adolescent girls ages 15 to 17 was higher in rural than urban areas ( $64 \%$ and $52 \%$, respectively) with a similar pattern for boys $(63 \%$ and $54 \%$ in rural and urban areas, respectively; Table 1). Similarly, the proportion of adolescent girls attending school at any one time in 2014 was higher in rural than in urban areas (74\% and 56\%, respectively), with the same pattern for boys ( $80 \%$ and $72 \%$, respectively). By contrast, the proportion of adolescent girls with secondary and higher educations was higher in urban than in rural areas $(61 \%$ and $42 \%$, respectively), with a similar pattern for boys ( $58 \%$ and $40 \%$, respectively). The proportion of adolescent girls from households in the top two wealth 
quintiles was also higher in urban than in rural areas (55\% and $47 \%$, respectively), while for boys the proportion was higher in rural than urban areas ( $47 \%$ and $40 \%$, respectively). There were no variations in the proportions of adolescent girls and boys ever been married, by type of place of residence ( $14 \%$ and $13 \%$ of urban and rural adolescent girls, respectively, and $1 \%$ of urban and rural adolescent boys).

\section{Sexual activity}

Slightly more than one third (37\%) of adolescent girls and 41 percent of adolescent boys had ever had sexual intercourse (Table 2). For both girls and boys, the proportion that had ever had sexual intercourse was highest among those aged 18 to 19 (60\% and 59\% for girls and boys, respectively), those who did not attend school at any time in 2014 ( $72 \%$ and $69 \%$, respectively), and those from second poorest households (44\% and $43 \%$, respectively). By contrast, the proportion of adolescent girls who had ever had sexual intercourse was highest among those with primary educations or no schooling, while for adolescent boys it was highest among those with secondary and higher educations. Sexual activity was slightly higher among adolescent girls who did not attend school at any time in 2014 than among a similar group of adolescent boys. Sexual activity was lower among never married adolescent girls compared to a similar group of adolescent boys ( $28 \%$ and $40 \%$, respectively).

Table 2: Distribution of adolescent girls and boys 15 to 19 years old who had ever had sexual intercourse, by background characteristics

\begin{tabular}{|c|c|c|c|c|c|c|}
\hline \multirow[b]{2}{*}{ Characteristics } & \multicolumn{2}{|c|}{ Urban } & \multicolumn{2}{|c|}{ Rural } & \multicolumn{2}{|c|}{ All sites } \\
\hline & $\begin{array}{c}\text { Female } \\
(\%)\end{array}$ & $\begin{array}{c}\text { Male } \\
(\%)\end{array}$ & $\begin{array}{c}\text { Female } \\
(\%)\end{array}$ & $\begin{array}{c}\text { Male } \\
(\%)\end{array}$ & $\begin{array}{c}\text { Female } \\
(\%)\end{array}$ & $\begin{array}{c}\text { Male } \\
(\%)\end{array}$ \\
\hline \multicolumn{7}{|l|}{ Age group (years) } \\
\hline $15-17$ & 24.8 & 26.0 & 21.5 & 28.9 & 22.4 & 28.2 \\
\hline $18-19$ & 58.9 & 61.2 & 60.0 & 58.2 & 59.6 & 59.2 \\
\hline \multicolumn{7}{|l|}{ Highest level of education } \\
\hline No schooling/primary & 47.4 & 40.1 & 36.8 & 38.1 & 39.3 & 38.5 \\
\hline Secondary and above & 37.0 & 43.6 & 33.4 & 42.5 & 34.8 & 42.9 \\
\hline \multicolumn{7}{|c|}{ Attended school at any time in 2014} \\
\hline No & 67.8 & 73.3 & 75.9 & 66.7 & 72.3 & 69.1 \\
\hline Yes & 19.3 & 30.0 & 21.2 & 33.3 & 20.7 & 32.5 \\
\hline \multicolumn{7}{|l|}{ Marital experience } \\
\hline Never married & 31.2 & 41.8 & 26.0 & 39.4 & 27.6 & 40.1 \\
\hline Ever marrieda & 100.0 & 100.0 & 100.0 & 100.0 & 100.0 & 100.0 \\
\hline \multicolumn{7}{|l|}{ Household wealth quintile } \\
\hline Lowest & 39.7 & 39.9 & 40.2 & 34.3 & 40.0 & 36.8 \\
\hline Second & 45.5 & 44.0 & 42.9 & 41.9 & 43.5 & 42.5 \\
\hline Middle & 51.4 & 43.0 & 34.0 & 41.5 & 38.4 & 41.9 \\
\hline Fourth & 43.8 & 32.3 & 35.7 & 41.2 & 37.9 & 39.1 \\
\hline Highest & 32.8 & 50.5 & 27.3 & 36.9 & 29.7 & 40.4 \\
\hline All respondents & 41.1 & 42.1 & 35.4 & 39.9 & 37.2 & 40.5 \\
\hline Number of respondents & 1,859 & 709 & 3,961 & 1,831 & 5,820 & 2,540 \\
\hline
\end{tabular}

Notes: aFormerly or currently married/living with a man/woman.

For both girls and boys, the proportions that had ever had sexual intercourse were higher in urban than in rural areas (41\% and $35 \%$, respectively for girls, $42 \%$ and $40 \%$, respectively, for boys; Table 2 ). Variations in sexual activity by age, education, school attendance, and marital status in urban and rural areas were largely similar to the patterns among all girls and boys. In urban areas, however, sexual activity was slightly lower among adolescent girls who did not attend school at any time in 2014 than among a similar group of boys (68\% and 
$73 \%$, respectively) while in rural areas it was higher among girls who did not attend school than among a similar group of boys ( $76 \%$ and $67 \%$, respectively).

Variations by county showed that the proportion of adolescent girls who had ever had sexual intercourse was highest in West Pokot (64\%) and lowest in Nyandarua (15\%; Table A1 in Appendix). Five counties with the highest proportion of adolescent girls who had ever had sexual intercourse include West Pokot, Migori, Samburu, Homa Bay, and Narok, while five counties with the lowest proportion include Nyandarua, Embu, Nyeri, Garissa, and Murang'a (Figure 1). Five counties with the highest proportion of adolescent girls from households in the bottom three wealth quintiles who had ever had sexual intercourse include Samburu (61\%), Kajiado (60\%), Migori (60\%), Homa Bay (56\%), and Nairobi (53\%), while five counties with the lowest proportions include Embu (16\%), Nyeri (19\%), Murang'a (21\%), Machakos (21\%), and Nyandarua (21\%; Table A1).

Figure 1: Counties with highest and lowest proportions of adolescent girls 15 to 19 years old who had ever had sexual intercourse

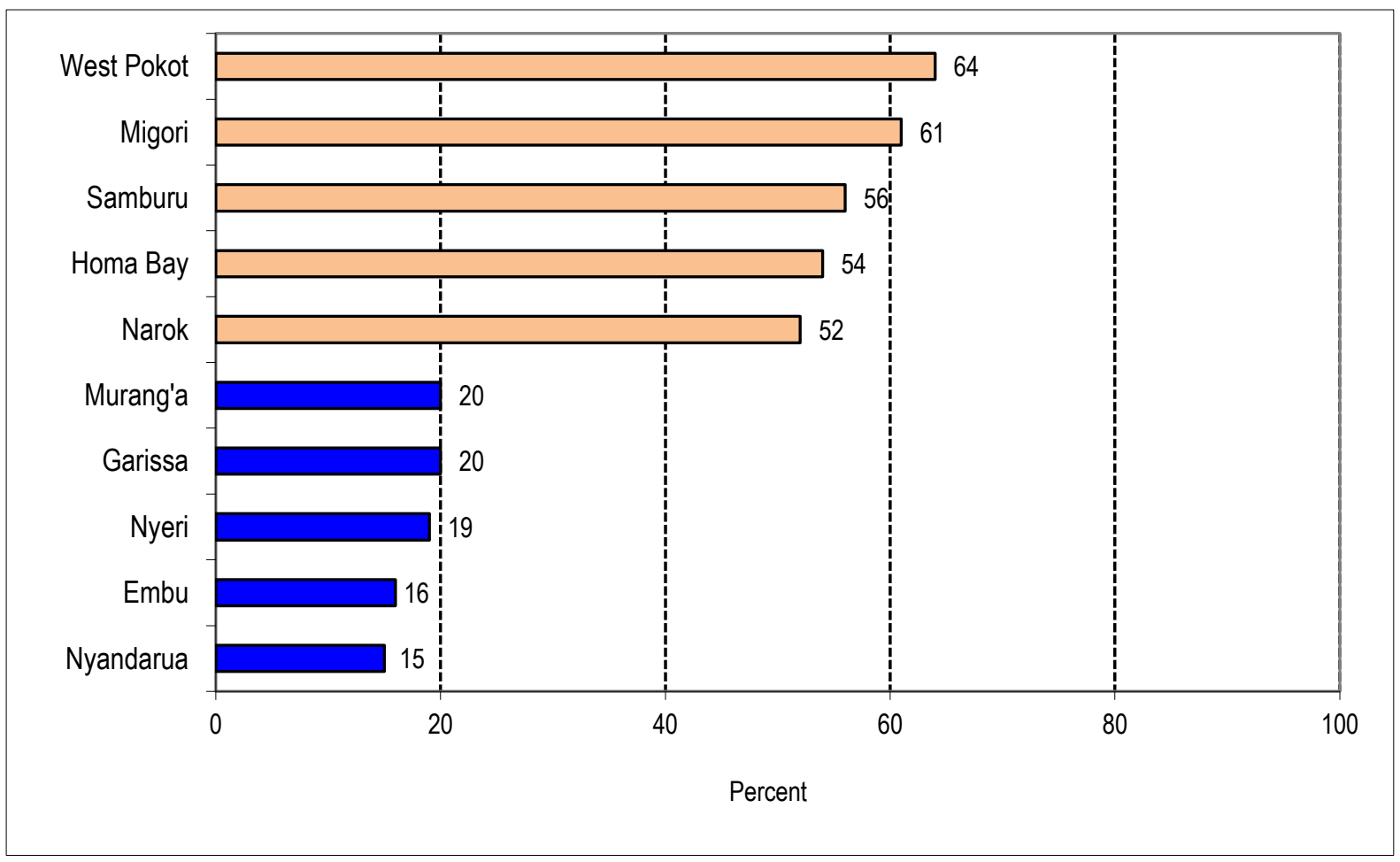

\section{Childbearing Experiences and Intentions}

\section{Childbearing Experiences}

Similar to the level in 2008-2009, 18 percent of adolescent girls 15 to 19 years old had begun childbearing (i.e. had ever given birth or were pregnant at the time of the 2014 survey), while only one percent of adolescent boys had ever impregnated a girl or had a partner who had given birth (Table 3 ). The proportion of adolescent girls who had begun childbearing was highest among those 18 to 19 years old, those with primary educations or no schooling, those who did not attend school at any time in 2014, ever married, and those from households in the bottom two wealth quintiles. These patterns were consistent in both urban and rural areas. Further analysis shows that among adolescent girls who had begun childbearing, 14 percent had given birth to at least two children, which represents a slight increase from the 2008-2009 level of 12 percent (not shown). 
Table 3: Distribution of adolescents girls and boys 15 to 19 years old who had begun childbearing, by background characteristics

\begin{tabular}{|c|c|c|c|c|c|c|}
\hline \multirow[b]{2}{*}{ Characteristics } & \multicolumn{2}{|c|}{ Urban } & \multicolumn{2}{|c|}{ Rural } & \multicolumn{2}{|c|}{ All sites } \\
\hline & $\begin{array}{r}\text { Female } \\
(\%)\end{array}$ & $\begin{array}{r}\text { Male } \\
(\%)\end{array}$ & $\begin{array}{r}\text { Female } \\
(\%)\end{array}$ & $\begin{array}{r}\text { Male } \\
(\%)\end{array}$ & $\begin{array}{r}\text { Female } \\
(\%)\end{array}$ & $\begin{array}{r}\text { Male } \\
(\%)\end{array}$ \\
\hline \multicolumn{7}{|l|}{ Age group (years) } \\
\hline $15-17$ & 9.1 & 0.1 & 8.2 & 0.2 & 8.5 & 0.1 \\
\hline $18-19$ & 26.3 & 1.8 & 36.7 & 1.7 & 32.7 & 1.8 \\
\hline \multicolumn{7}{|l|}{ Highest level of education } \\
\hline No schooling/primary & 27.0 & 1.3 & 23.2 & 0.8 & 24.1 & 0.9 \\
\hline Secondary and above & 11.1 & 0.6 & 11.8 & 0.7 & 11.5 & 0.6 \\
\hline \multicolumn{7}{|c|}{ Attended school at any time in 2014} \\
\hline No & 34.6 & 3.0 & 57.9 & 3.1 & 47.5 & 3.0 \\
\hline Yes & 2.7 & 0.0 & 4.6 & 0.2 & 4.1 & 0.1 \\
\hline \multicolumn{7}{|l|}{ Marital experience } \\
\hline Never married & 6.7 & 0.7 & 8.5 & 0.3 & 8.0 & 0.4 \\
\hline Ever marrieda & 80.4 & 21.5 & 87.1 & 62.1 & 84.8 & 52.8 \\
\hline \multicolumn{7}{|l|}{ Household wealth quintile } \\
\hline Lowest & 20.2 & 0.5 & 24.7 & 1.4 & 22.9 & 1.0 \\
\hline Second & 26.0 & 2.1 & 26.0 & 1.3 & 26.0 & 1.5 \\
\hline Middle & 27.6 & 0.2 & 16.9 & 0.6 & 19.6 & 0.5 \\
\hline Fourth & 18.7 & 0.0 & 18.6 & 0.6 & 18.6 & 0.4 \\
\hline Highest & 6.3 & 1.4 & 10.2 & 0.4 & 8.5 & 0.7 \\
\hline All respondents & 17.3 & 0.9 & 18.5 & 0.8 & 18.1 & 0.8 \\
\hline Number of respondents & 1,859 & 709 & 3,961 & 1,831 & 5,820 & 2,540 \\
\hline
\end{tabular}

Notes: aFormerly or currently married/living with a man/woman.

County variations show Narok with the highest proportion of adolescent girls that had begun childbearing, while Nyeri had the lowest (Table A2). Homa Bay, West Pokot, Tana River, and Nyamira were in the top five counties with the highest proportions, while Elgeyo Marakwet, Nyandarua, and Lamu were counties with the lowest proportions of adolescent girls who had begun childbearing (Figure 2). Five counties with the highest proportion of girls from households in the bottom three wealth quintiles that had begun childbearing include Narok, Kajiado, Homa Bay, Kwale, and Mombasa, while counties with the lowest proportions include Murang'a, Elgeyo Marakwet, Nyeri, Embu, and Isiolo (Table A2).

Figure 2: Counties with highest and lowest proportions of adolescent girls who had begun childbearing

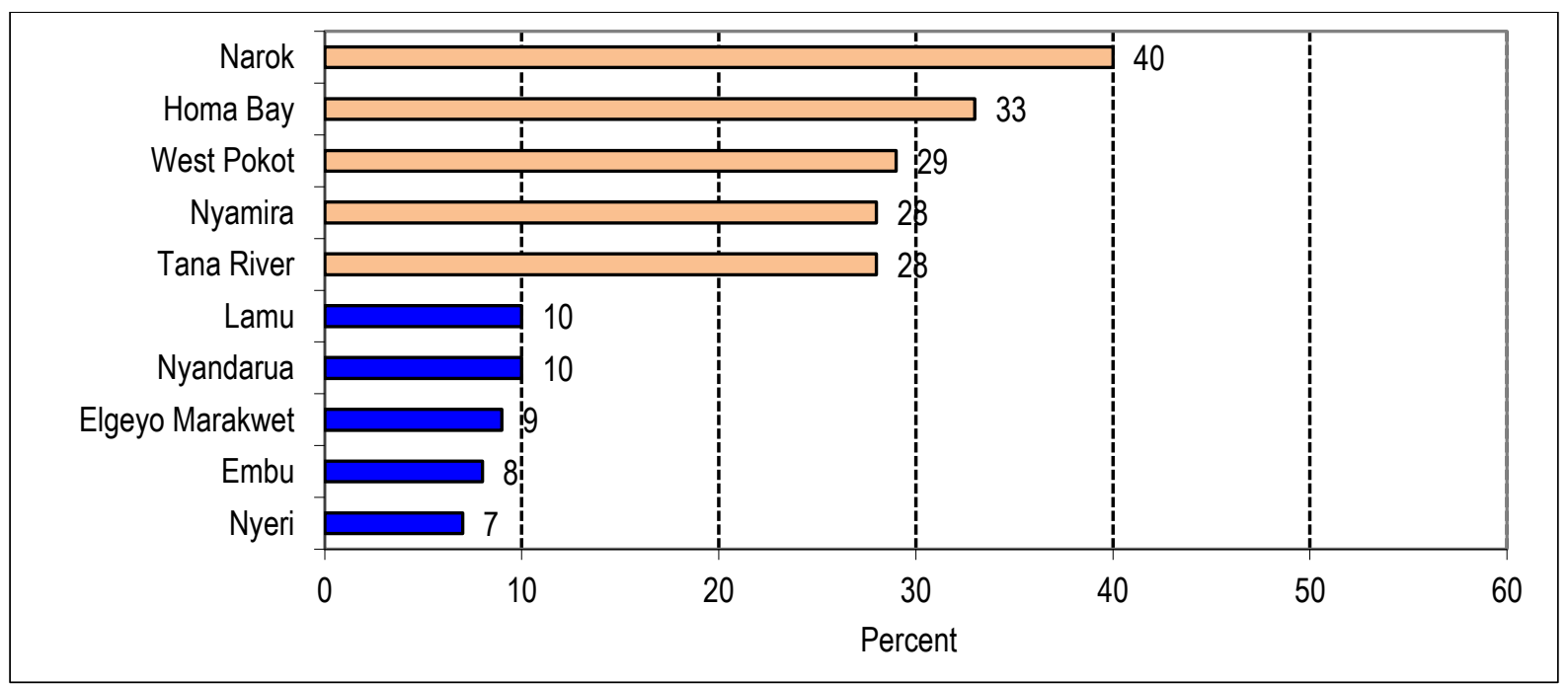




\section{Unintended Pregnancy}

More than one quarter $(29 \%)$ of adolescent girls who had begun childbearing reported ever having an unintended pregnancy, a previous birth or current pregnancy either wanted later $(28.8 \%)$ or not at all $(0.2 \%)$. The proportion of adolescent girls reporting experiencing unintended pregnancy was higher in rural than in urban areas (30\% and $28 \%$, respectively; Table 4). The proportion was also highest among those 15 to 17 years old, those with secondary and higher educations, those who attended school at any time in 2014, and never married individuals. These patterns were consistent in both urban and rural areas. In urban areas, however, the proportion was highest among girls from households in the middle wealth quintile, while in rural areas it was highest among those from households in the top wealth quintiles (Table 4).

Table 4: Distribution of adolescent girls 15 to 19 years old who experienced unintended pregnancy, among those who had begun childbearing, by background characteristics

\begin{tabular}{|lcccccc|}
\hline \multirow{2}{*}{ Characteristics } & \multicolumn{2}{c}{ Urban } & \multicolumn{2}{c}{ Rural } & \multicolumn{2}{c|}{ All sites } \\
\cline { 2 - 6 } & Percent & $\begin{array}{c}\text { Number } \\
\text { of cases }\end{array}$ & Percent & $\begin{array}{c}\text { Number } \\
\text { of cases }\end{array}$ & Percent & $\begin{array}{c}\text { Number } \\
\text { of cases }\end{array}$ \\
\hline Age group (years) & & & & & & \\
\hline $15-17$ & 30.9 & 89 & 34.1 & 208 & 33.2 & 297 \\
$18-19$ & 26.5 & 233 & 27.8 & 523 & 27.4 & 756 \\
\hline Highest level of education & & & & & & \\
\hline No schooling/primary & 24.6 & 196 & 24.8 & 536 & 24.7 & 732 \\
Secondary and above & 32.7 & 126 & 42.8 & 195 & 38.8 & 321 \\
\hline Attended school at any time in 2014 & & & & & & \\
\hline No & 25.4 & 279 & 27.2 & 579 & 26.6 & 858 \\
Yes & 47.0 & 28 & 40.6 & 135 & 41.7 & 163 \\
\hline Marital experience & & & & & & \\
\hline Never married & 38.3 & 106 & 45.7 & 296 & 44.0 & 402 \\
$\quad$ Ever marrieda & 22.1 & 216 & 18.6 & 435 & 19.8 & 651 \\
\hline Household wealth quintile & & & & & & \\
\hline Lowest & 24.1 & 50 & 20.3 & 94 & 21.6 & 144 \\
Second & 16.9 & 72 & 27.0 & 203 & 24.4 & 275 \\
$\quad$ Middle & 41.9 & 88 & 34.5 & 159 & 37.1 & 247 \\
$\quad$ Fourth & 24.6 & 73 & 27.4 & 189 & 26.6 & 262 \\
$\quad$ Highest & 26.6 & 39 & 41.4 & 86 & 36.7 & 125 \\
\hline All respondents & 27.8 & 322 & 29.6 & 731 & 29.0 & 1,053 \\
\hline Notes: aFormerly or currently married/living with a man. & & & & & \\
\hline
\end{tabular}

Notes: $\quad$ aFormerly or currently married/living with a man.

\section{Use of Contraception}

\section{Current Use of Contraception}

Slightly more than one quarter (27\%) of adolescent girls and 44 percent of adolescent boys who had ever had sexual intercourse reported using a method of contraception at the time of the survey, with a large proportion ( $25 \%$ of girls and $43 \%$ of boys) using modern methods (Table 5 ). For both girls and boys, the proportion using any method or modern methods was higher in urban than in rural areas. In addition, the proportion using modern methods was highest among those 18 to 19 years old and those who did not attend school at any time in 2014. For girls, there was no difference in use of modern methods by education $(25 \%$ among those with primary or no education and a similar proportion among those with secondary and higher educations), while use was highest 
among those married or living with a man at the time of the survey. For boys, use of modern methods was highest among never married individuals and those with secondary and higher educations. For both girls and boys, use of modern methods was lowest among those from the poorest households.

Table 5: Sexually active adolescent girls and boys 15 to 19 years old using contraception, by background

\begin{tabular}{|c|c|c|c|c|c|c|}
\hline \multirow{3}{*}{ Characteristics } & \multicolumn{6}{|c|}{ Current use of any method } \\
\hline & \multicolumn{2}{|c|}{ Urban } & \multicolumn{2}{|c|}{ Rural } & \multicolumn{2}{|c|}{ All sites } \\
\hline & $\begin{array}{c}\text { Female } \\
(\%)\end{array}$ & $\begin{array}{c}\text { Male } \\
(\%)\end{array}$ & $\begin{array}{c}\text { Female } \\
(\%)\end{array}$ & $\begin{array}{c}\text { Male } \\
(\%)\end{array}$ & $\begin{array}{c}\text { Female } \\
(\%)\end{array}$ & $\begin{array}{c}\text { Male } \\
(\%)\end{array}$ \\
\hline \multicolumn{7}{|l|}{ Age group (years) } \\
\hline $15-17$ & 36.1 & 46.8 & 18.0 & 31.6 & 20.5 & 35.1 \\
\hline $18-19$ & 35.0 & 53.9 & 28.5 & 49.1 & 31.0 & 50.7 \\
\hline \multicolumn{7}{|l|}{ Highest level of education } \\
\hline No schooling/primary & 33.7 & 44.4 & 23.9 & 34.4 & 26.7 & 36.7 \\
\hline Secondary and above & 30.9 & 56.2 & 25.2 & 50.2 & 27.7 & 52.4 \\
\hline \multicolumn{7}{|l|}{ Attended school at any time in 2014} \\
\hline No & 35.2 & 52.8 & 31.3 & 46.2 & 32.9 & 48.7 \\
\hline Yes & 22.9 & 50.6 & 15.4 & 39.1 & 17.2 & 41.9 \\
\hline \multicolumn{7}{|l|}{ Current marital status } \\
\hline Unmarrieda & 23.4 & 51.7 & 19.6 & 41.4 & 21.0 & 44.4 \\
\hline Married/living with a man/woman & 51.4 & 28.6 & 34.3 & 29.0 & 40.2 & 28.9 \\
\hline \multicolumn{7}{|l|}{ Household wealth quintile } \\
\hline Lowest & 33.3 & 35.7 & 13.5 & 39.0 & 21.3 & 37.4 \\
\hline Second & 33.2 & 41.6 & 20.3 & 38.1 & 23.8 & 39.2 \\
\hline Middle & 37.5 & 58.4 & 26.7 & 40.5 & 30.4 & 45.1 \\
\hline Fourth & 34.7 & 54.4 & 29.3 & 42.6 & 31.0 & 44.9 \\
\hline Highest & 24.6 & 63.7 & 26.8 & 44.1 & 25.8 & 50.4 \\
\hline \multirow[t]{2}{*}{ All respondents } & 32.2 & 51.5 & 24.4 & 41.2 & 27.1 & 44.2 \\
\hline & \multicolumn{6}{|c|}{ Current use of a modern method } \\
\hline \multicolumn{7}{|l|}{ Age group (years) } \\
\hline $15-17$ & 25.1 & 41.5 & 16.4 & 30.6 & 19.1 & 33.1 \\
\hline $18-19$ & 32.7 & 52.3 & 25.7 & 47.9 & 28.3 & 49.3 \\
\hline \multicolumn{7}{|l|}{ Highest level of education } \\
\hline No schooling/primary & 32.0 & 38.8 & 21.9 & 34.3 & 24.8 & 35.3 \\
\hline Secondary and above & 28.8 & 55.1 & 22.3 & 47.7 & 25.1 & 50.4 \\
\hline \multicolumn{7}{|l|}{ Attended school at any time in 2014} \\
\hline No & 33.1 & 47.9 & 28.2 & 45.6 & 30.3 & 46.5 \\
\hline Yes & 21.5 & 49.6 & 13.9 & 37.7 & 15.8 & 40.5 \\
\hline \multicolumn{7}{|l|}{ Current marital status } \\
\hline Unmarrieda $^{a}$ & 22.3 & 48.8 & 17.7 & 40.2 & 19.4 & 42.7 \\
\hline Married/living with a man/woman & 47.7 & 28.6 & 31.1 & 29.0 & 36.8 & 28.9 \\
\hline \multicolumn{7}{|l|}{ Household wealth quintile } \\
\hline Lowest & 33.2 & 32.4 & 11.2 & 36.6 & 19.8 & 34.6 \\
\hline Second & 32.8 & 39.0 & 18.6 & 37.7 & 22.5 & 38.1 \\
\hline Middle & 33.8 & 50.8 & 23.7 & 38.8 & 27.1 & 41.9 \\
\hline Fourth & 30.9 & 54.4 & 28.0 & 42.6 & 28.9 & 44.9 \\
\hline Highest & 24.0 & 63.3 & 22.7 & 41.8 & 23.3 & 48.7 \\
\hline All respondents & 30.3 & 48.7 & 22.1 & 40.0 & 25.0 & 42.5 \\
\hline Number of respondents & 764 & 299 & 1,400 & 730 & 2,164 & 1,029 \\
\hline
\end{tabular}

Notes: $\quad$ aNever or formerly married. 
There were variations in patterns of use of modern methods among adolescent girls and boys in urban and rural areas. For instance, among adolescent girls in urban areas, use of modern methods was slightly higher among those with primary or no educations than those with secondary and higher educations ( $32 \%$ and $29 \%$,

respectively; Table 5). In addition, use of the methods was lowest among those from the richest households. By contrast, there was no difference in use of modern methods by education among adolescent girls in rural areas (22\% each), while use was lowest among those from poorest households. Overall variations of use of modern methods among adolescent girls by these characteristics are therefore largely driven by the patterns in rural areas.

Among boys in urban areas, use of modern methods was slightly higher among those who attended school at any time in 2014 than those who did not (50\% and 48\%, respectively), while in rural areas use was higher among those who did not attend school than those who did ( $46 \%$ and $38 \%$, respectively). Use of modern methods among boys increased with household socio-economic status in both urban and rural areas, however.

Mombasa county had the highest proportion (52\%) of sexually active adolescent girls using any method of contraception, while Garissa and Mandera had none (Table A3). Machakos, Kiambu, Trans-Nzoia, and Makueni were among the top five counties with highest proportions of adolescent girls using any method of contraception, while Samburu, Marsabit, Turkana, Wajir, and West Pokot had the lowest (Table A3). Variations in use of modern methods show that Kiambu, Kirinyaga, Machakos, Mombasa, and Kisii had the highest proportions of sexually active adolescent girls using contraceptive methods, while Narok, Turkana, Murang'a, Marsabit, West Pokot, and Wajir had the lowest (Figure 3).

Figure 3: Counties with highest and lowest proportions of sexually active adolescent girls using modern methods of contraception

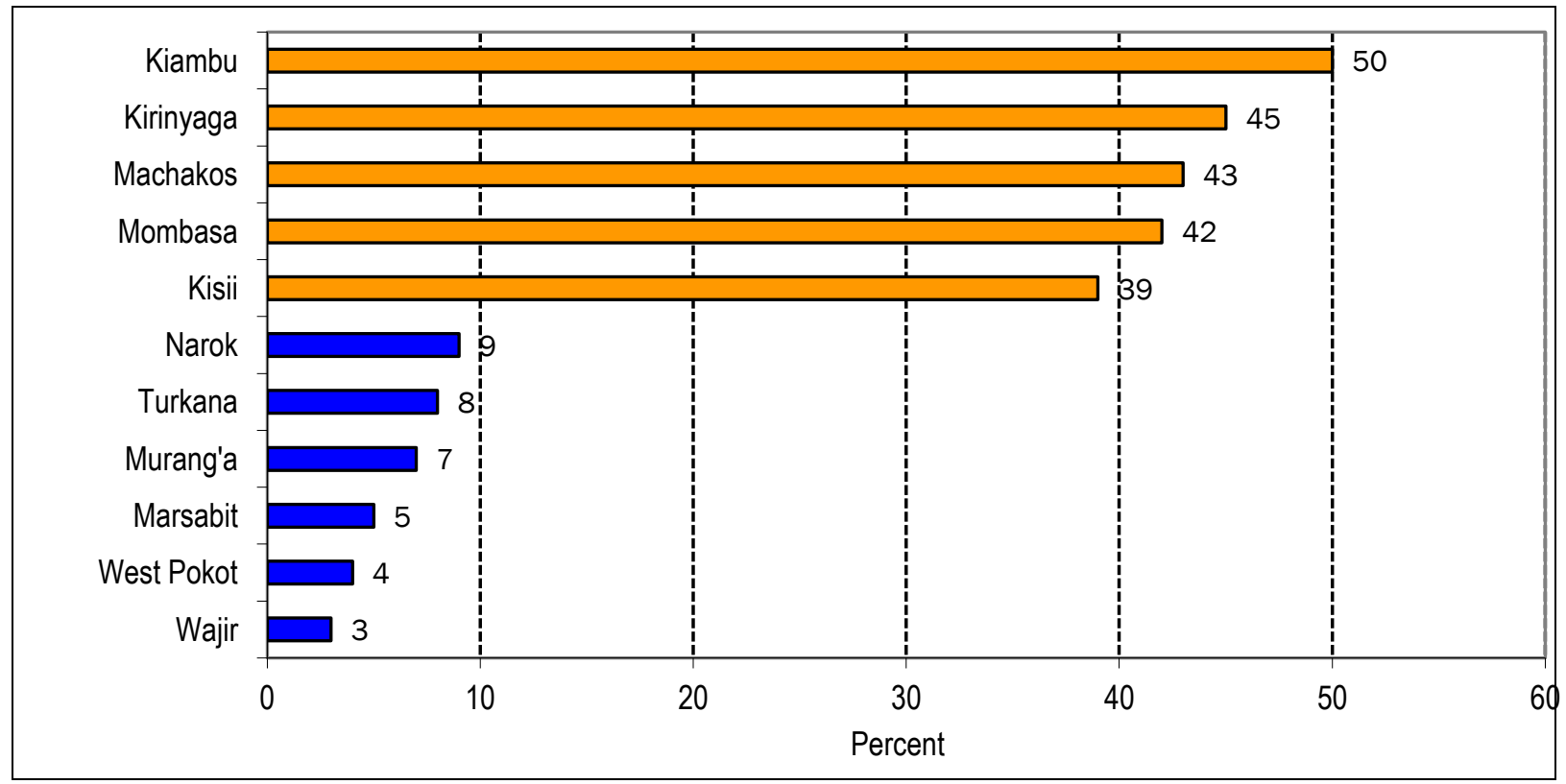

\section{Method Mix}

The most commonly used methods by sexually active adolescent girls were injectables $(48 \%)$, condoms $(26 \%)$, and implants (12\%; Figure 4). Although these patterns were consistent in both urban and rural areas, use of injectables was higher in rural than in urban areas ( $53 \%$ and $42 \%$, respectively) while use of condoms, implants, and pills was higher in urban than in rural areas. 
Figure 4: Method mix among sexually active adolescent girls 15 to 19 years old using contraception

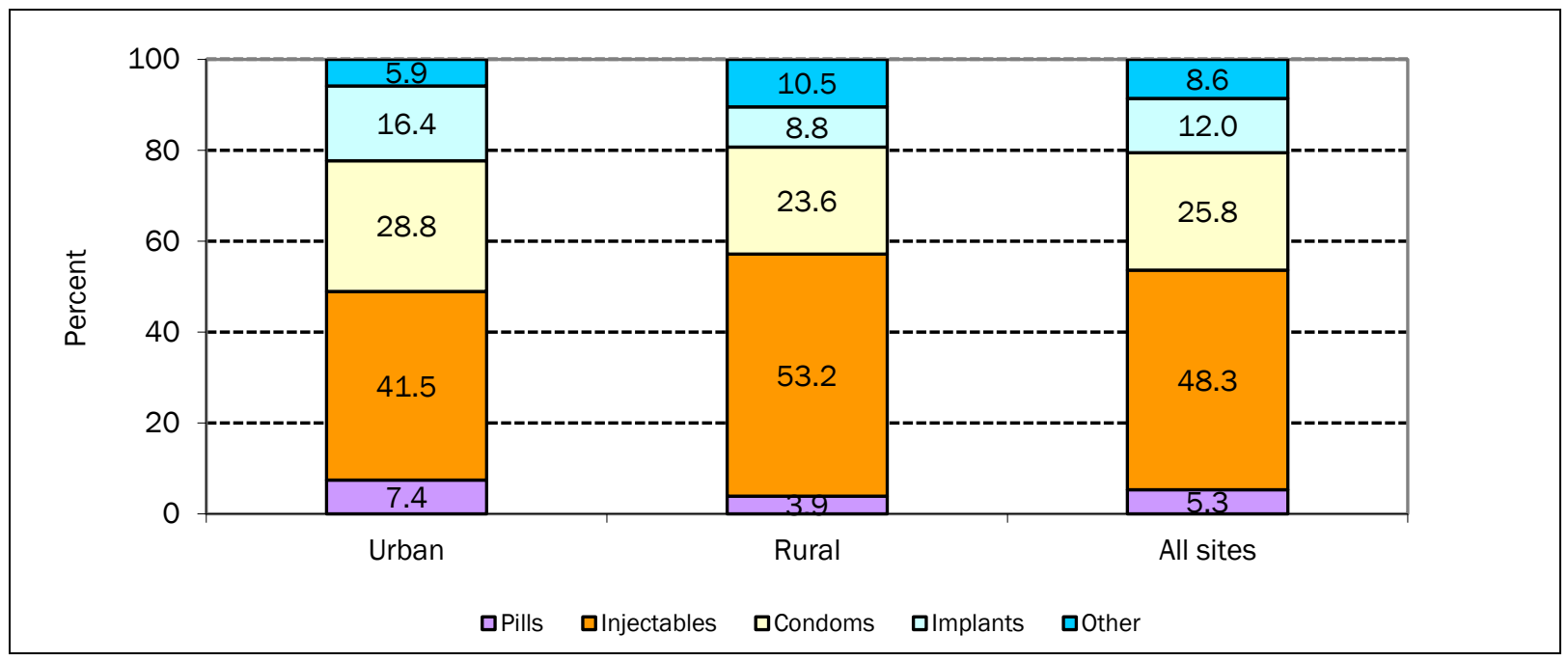

\section{Sources of Contraception}

Most adolescent girls using contraception (47\%) obtained their method from public health facilities, 25 percent obtained them from private health facilities, while another 20 percent obtained them from other sources including shops, mobile clinics, community-based distributors, and friends or relatives. The proportion that obtained methods from public health facilities was highest among those aged 18 to 19 , those with primary education or no schooling, those who did not attend school at any time in 2014, married individuals, and those from the poorest households (Table 6). By contrast, the proportion that obtained methods from private facilities was highest among those 15 to 17 years old, those with secondary and higher educations, and those from the richest households.

Table 6: Sources of contraception for adolescent girls 15 to 19 years old, by background characteristics

\begin{tabular}{|c|c|c|c|c|c|c|c|c|c|}
\hline \multirow[b]{2}{*}{ Characteristics } & \multicolumn{3}{|c|}{ Urban } & \multicolumn{3}{|c|}{ Rural } & \multicolumn{3}{|c|}{ All sites } \\
\hline & $\begin{array}{c}\text { Public } \\
(\%)\end{array}$ & $\begin{array}{c}\text { Private } \\
(\%)\end{array}$ & $\begin{array}{l}\text { Number } \\
\text { of cases }\end{array}$ & $\begin{array}{c}\text { Public } \\
(\%)\end{array}$ & $\begin{array}{c}\text { Private } \\
(\%)\end{array}$ & $\begin{array}{l}\text { Number } \\
\text { of cases }\end{array}$ & $\begin{array}{c}\text { Public } \\
(\%)\end{array}$ & $\begin{array}{c}\text { Private } \\
(\%)\end{array}$ & $\begin{array}{l}\text { Number } \\
\text { of cases }\end{array}$ \\
\hline \multicolumn{10}{|l|}{ Age group (years) } \\
\hline $15-17$ & 10.8 & 51.5 & 63 & 41.1 & 16.9 & 98 & 29.2 & 30.5 & 161 \\
\hline $18-19$ & 41.5 & 36.0 & 183 & 62.0 & 13.3 & 244 & 53.2 & 23.0 & 427 \\
\hline \multicolumn{10}{|l|}{ Highest level of education } \\
\hline No schooling/primary & 38.4 & 38.9 & 116 & 66.9 & 15.2 & 203 & 56.5 & 23.8 & 319 \\
\hline Secondary and above & 29.4 & 40.9 & 130 & 40.1 & 13.0 & 139 & 34.9 & 26.5 & 269 \\
\hline \multicolumn{10}{|c|}{ Attended school at any time in 2014} \\
\hline No & 35.6 & 43.2 & 194 & 64.3 & 15.9 & 237 & 51.4 & 28.1 & 431 \\
\hline Yes & 18.3 & 31.4 & 45 & 34.1 & 10.0 & 96 & 29.0 & 16.9 & 141 \\
\hline \multicolumn{10}{|l|}{ Current marital status } \\
\hline Unmarrieda $^{a}$ & 21.0 & 36.3 & 124 & 40.9 & 16.3 & 185 & 32.9 & 24.3 & 309 \\
\hline Married/living together & 46.3 & 43.7 & 122 & 73.9 & 12.0 & 157 & 61.8 & 25.9 & 279 \\
\hline \multicolumn{10}{|l|}{ Household wealth quintile } \\
\hline Lowest & 58.1 & 10.5 & 33 & 79.1 & 3.8 & 21 & 66.2 & 7.9 & 54 \\
\hline Second & 42.2 & 39.9 & 41 & 71.3 & 5.9 & 68 & 60.2 & 18.9 & 109 \\
\hline Middle & 27.1 & 36.0 & 62 & 40.9 & 22.5 & 85 & 35.1 & 28.2 & 147 \\
\hline Fourth & 35.4 & 41.7 & 59 & 56.9 & 17.5 & 106 & 49.2 & 26.1 & 165 \\
\hline Highest & 16.8 & 61.6 & 51 & 50.8 & 10.2 & 62 & 35.4 & 33.5 & 113 \\
\hline All female respondents & 33.6 & 40.0 & 246 & 56.0 & 14.3 & 342 & 46.6 & 25.1 & 588 \\
\hline
\end{tabular}


There were variations in the proportions of adolescent girls who obtained methods from public or private facilities by urban or rural residence. The proportion that obtained methods from private facilities was higher than from public facilities in urban areas ( $40 \%$ and $34 \%$, respectively), while in rural areas a higher proportion obtained their methods from public rather than private facilities ( $56 \%$ and $14 \%$, respectively). Variations in sources of contraception by age, school attendance, and household wealth quintile in urban and rural areas were similar to overall patterns. Unlike the overall patterns, however, the proportion that obtained methods from private facilities in rural areas was slightly higher among those with primary education or less than those with secondary and higher educations, and among unmarried than married individuals. Overall variations in use of private facilities by these characteristics were therefore largely driven by patterns in urban areas.

Unlike adolescent girls, only about one third (32\%) of adolescent boys using condoms obtained them from a health facility (public or private), with 66 percent obtaining them from other sources. Similar to adolescent girls, the proportion obtaining condoms from private facilities was higher than for public facilities in urban areas ( $15 \%$ and $10 \%$, respectively) while in rural areas a higher proportion obtained them from public rather than private facilities (31\% and $5 \%$, respectively; Table 7 ). In addition, the proportion of boys who obtained condoms from public facilities was highest among those of primary educations or no schooling, those who attended school at any time in 2014, and those from the poorest households. By contrast, the proportion that obtained condoms from private facilities was highest among those 15 to 17 years old, with secondary and higher education, those who did not attend school at any time in 2014, and those from the richest households.

Table 7: Sources of condoms for adolescent boys 15 to 19 years old, by background characteristics

\begin{tabular}{|c|c|c|c|c|c|c|c|c|c|}
\hline \multirow[b]{2}{*}{ Characteristics } & \multicolumn{3}{|c|}{ Urban } & \multicolumn{3}{|c|}{ Rural } & \multicolumn{3}{|c|}{ All sites } \\
\hline & $\begin{array}{l}\text { Publi } \\
\text { c(\%) }\end{array}$ & $\begin{array}{c}\text { Private } \\
(\%)\end{array}$ & $\begin{array}{l}\text { Number } \\
\text { of cases }\end{array}$ & $\begin{array}{c}\text { Public } \\
(\%)\end{array}$ & $\begin{array}{l}\text { Private } \\
(\%)\end{array}$ & $\begin{array}{l}\text { Number } \\
\text { of cases }\end{array}$ & $\begin{array}{c}\text { Public } \\
(\%)\end{array}$ & $\begin{array}{l}\text { Private } \\
(\%)\end{array}$ & $\begin{array}{l}\text { Number } \\
\text { of cases }\end{array}$ \\
\hline \multicolumn{10}{|l|}{ Age group (years) } \\
\hline $15-17$ & 11.5 & 26.8 & 41 & 32.4 & 5.9 & 94 & 26.1 & 12.3 & 135 \\
\hline $18-19$ & 9.2 & 10.6 & 97 & 29.5 & 4.8 & 178 & 22.3 & 6.8 & 275 \\
\hline \multicolumn{10}{|l|}{ Highest level of education } \\
\hline No schooling/primary & 15.5 & 7.6 & 45 & 31.4 & 3.3 & 140 & 27.6 & 4.4 & 185 \\
\hline Secondary and above & 7.2 & 19.1 & 93 & 29.5 & 7.2 & 132 & 20.3 & 12.1 & 225 \\
\hline \multicolumn{10}{|c|}{ Attended school at any time in 2014} \\
\hline No & 8.9 & 21.7 & 63 & 25.1 & 5.4 & 100 & 18.8 & 11.7 & 163 \\
\hline Yes & 10.7 & 10.1 & 75 & 33.7 & 5.1 & 171 & 26.8 & 6.6 & 246 \\
\hline \multicolumn{10}{|l|}{ Household wealth quintile } \\
\hline Lowest & 31.2 & 3.3 & 14 & 21.8 & 8.4 & 19 & 25.9 & 6.2 & 33 \\
\hline Second & 13.4 & 13.3 & 27 & 43.9 & 2.4 & 54 & 33.8 & 6.0 & 81 \\
\hline Middle & 13.0 & 12.6 & 32 & 27.9 & 5.3 & 66 & 23.0 & 7.7 & 98 \\
\hline Fourth & 0.6 & 3.5 & 19 & 31.8 & 3.7 & 77 & 25.7 & 3.6 & 96 \\
\hline Highest & 2.5 & 27.3 & 46 & 21.9 & 8.3 & 56 & 13.3 & 17.0 & 102 \\
\hline All male respondents & 9.9 & 15.4 & 138 & 30.5 & 5.2 & 272 & 23.6 & 8.6 & 410 \\
\hline
\end{tabular}

Notes: $\quad$ aNever or formerly married.

\section{Unmet Need for Contraception}

Unmet need for contraception was higher among married adolescent girls (23\%) than among all married women $(18 \%)$, although more for spacing (22\%) than limiting births (1\%), unlike for all married women, for whom it was equally for spacing and limiting. Unmet need was highest among those 18 to 19 years old (25\%), those with primary education or no schooling (24\%), and those from the poorest households (32\%; Table 8). Unmet need was also higher in rural than urban areas (29\% and $14 \%)$. There were urban and rural variations in unmet need by age, education, and household wealth index. In urban areas, unmet need was highest among those 15 to 17 
years old, those with primary or no schooling, and those from the poorest households. By contrast, unmet need in rural areas was highest among those 18 to 19 years old, those with secondary and higher educations, and those from households in the extreme and middle quintiles (Table 8).

Table 8: Currently married adolescent girls 15 to 19 years old with unmet contraceptive need, by background

\begin{tabular}{|l|cc|cc|cc|}
\hline \multirow{2}{*}{ Characteristics } & \multicolumn{2}{|c|}{ Urban } & \multicolumn{2}{c|}{ Rural } & \multicolumn{2}{c|}{ All sites } \\
\cline { 2 - 7 } & Percent & $\begin{array}{c}\text { Number } \\
\text { of cases }\end{array}$ & Percent & $\begin{array}{c}\text { Number } \\
\text { of cases }\end{array}$ & Percent & $\begin{array}{c}\text { Number } \\
\text { of cases }\end{array}$ \\
\hline Age group (years) & & & & & & \\
\hline $15-17$ & 17.6 & 30 & 19.0 & 46 & 18.4 & 76 \\
$18-19$ & 12.3 & 81 & 31.8 & 142 & 24.8 & 223 \\
\hline Highest level of education & & & & & & \\
\hline No schooling/primary & 19.6 & 61 & 25.1 & 148 & 23.5 & 209 \\
Secondary and above & 6.6 & 50 & 41.9 & 40 & 22.4 & 90 \\
\hline Household wealth quintile & & & & & & \\
\hline Lowest & 31.5 & 14 & 31.5 & 36 & 31.5 & 50 \\
Second & 13.8 & 18 & 25.1 & 62 & 22.5 & 80 \\
Middle & 19.3 & 35 & 33.5 & 38 & 26.7 & 73 \\
Fourth & 4.3 & 39 & 25.5 & 35 & 14.3 & 75 \\
Highest & 0.0 & 5 & 31.8 & 17 & 24.8 & 21 \\
\hline All respondents & 13.7 & 111 & 28.7 & 188 & 23.2 & 299 \\
\hline
\end{tabular}

\section{Intention to Use Contraception}

More than two thirds $(71 \%)$ of adolescent girls not currently using contraception intend to use a method in future, with the majority (52\%) intending to use a modern method, while a substantial proportion (18\%) did not know the method they intend to use (Table 9). The proportion that intends to use a modern method was highest among those 18 to 19 years old, those with secondary and higher educations, those who did not attend school at any time in 2014, married individuals, and those from households in the top two wealth quintiles. The proportion that did not know the method they intend to use was, on the other hand, highest among those 15 to 17 years old, those who attended school at any time in 2014, and unmarried individuals. A high proportion of those with secondary and higher educations and those from the richest households also reported that they did not know the method that they intend to use ( $20 \%$ and $21 \%$, respectively). The proportion that did not intend to use a method in future was highest among those 15 to 17 years old, those with primary or no schooling, those who attended school at any time in 2014, married individuals, and those from the poorest households.

The proportions of non-users who intend to use a method in future were similar in both urban and rural areas ( $72 \%$ and $71 \%$ in urban and rural areas, respectively; Table 9$)$. The proportion that did not know the method they intend to use was higher in urban than in rural areas (22\% and $16 \%$, respectively), however, while the proportion that intended to use a modern method was higher in rural than in urban areas (54\% and $49 \%$, respectively). In both urban and rural areas, the proportion of adolescent girls who intended to use a modern method in future was highest among those 18 to 19 years old, those who did not attend school at any time in 2014, and married individuals. The proportion in urban areas that intended to use a modern method was slightly higher among those with primary or no schooling, however, than among those with secondary and higher educations $(50 \%$ and $48 \%$ respectively). By contrast, the proportion in rural areas that intended to use such methods was higher among those with secondary and higher educations than among those with primary or no schooling $(60 \%$ and $49 \%$, respectively). In addition, the proportions in urban areas that intended to use a modern method were highest among adolescent girls from households in the extreme ends of the wealth quintile distribution (lowest and highest), while in rural areas, the proportion increased with socio-economic status (Table 9). 
Table 9: Distribution of adolescent girls 15 to 19 years old not currently using contraception who intend to use a method in future, by background characteristics and type of method

\begin{tabular}{|c|c|c|c|c|c|c|c|c|c|c|c|c|c|c|c|}
\hline \multirow[t]{2}{*}{ Characteristics } & \multicolumn{3}{|c|}{ Modern method } & \multicolumn{3}{|c|}{ Traditional method } & \multicolumn{3}{|c|}{ Don't know method } & \multicolumn{3}{|c|}{ Does not intend to use } & \multicolumn{3}{|c|}{ Number of cases } \\
\hline & $\begin{array}{l}\text { All } \\
\text { sites }\end{array}$ & $\begin{array}{l}\text { Urban } \\
\text { areas }\end{array}$ & $\begin{array}{l}\text { Rural } \\
\text { areas }\end{array}$ & $\begin{array}{l}\text { All } \\
\text { sites }\end{array}$ & $\begin{array}{l}\text { Urban } \\
\text { areas }\end{array}$ & $\begin{array}{l}\text { Rural } \\
\text { areas }\end{array}$ & $\begin{array}{l}\text { All } \\
\text { sites }\end{array}$ & $\begin{array}{l}\text { Urban } \\
\text { areas }\end{array}$ & $\begin{array}{l}\text { Rural } \\
\text { areas }\end{array}$ & $\begin{array}{l}\text { All } \\
\text { sites }\end{array}$ & $\begin{array}{l}\text { Urban } \\
\text { areas }\end{array}$ & $\begin{array}{l}\text { Rural } \\
\text { areas }\end{array}$ & $\begin{array}{l}\text { All } \\
\text { sites }\end{array}$ & $\begin{array}{l}\text { Urban } \\
\text { areas }\end{array}$ & $\begin{array}{l}\text { Rural } \\
\text { areas }\end{array}$ \\
\hline \multicolumn{16}{|l|}{ Age group (years) } \\
\hline $15-17$ & 47.6 & 42.6 & 49.4 & 1.0 & 1.1 & 0.9 & 19.5 & 24.5 & 17.6 & 31.9 & 31.8 & 32.0 & 1,593 & 425 & 1,168 \\
\hline $18-19$ & 61.4 & 56.9 & 63.8 & 1.2 & 1.4 & 1.1 & 13.9 & 17.9 & 11.7 & 23.5 & 23.8 & 23.4 & 842 & 297 & 546 \\
\hline \multicolumn{16}{|l|}{ Highest level of education } \\
\hline No schooling/primary & 49.3 & 49.5 & 49.2 & 0.6 & 1.0 & 0.5 & 15.5 & 14.7 & 15.7 & 34.7 & 34.9 & 34.6 & 1,222 & 243 & 980 \\
\hline Secondary and above & 55.5 & 48.0 & 60.4 & 1.5 & 1.3 & 1.7 & 19.6 & 25.4 & 15.8 & 23.4 & 25.3 & 22.1 & 1,213 & 479 & 734 \\
\hline \multicolumn{16}{|c|}{ Attended school at any time in 2014} \\
\hline No & 62.5 & 61.3 & 63.4 & 1.2 & 1.2 & 1.2 & 11.4 & 15.8 & 8.1 & 24.9 & 21.7 & 27.2 & 629 & 264 & 365 \\
\hline Yes & 48.9 & 41.4 & 51.5 & 1.0 & 1.2 & 0.9 & 19.6 & 24.9 & 17.8 & 30.5 & 32.5 & 29.8 & 1,795 & 455 & 1,340 \\
\hline \multicolumn{16}{|l|}{ Current marital status } \\
\hline Unmarrieda & 51.0 & 46.6 & 52.8 & 1.0 & 1.1 & 1.0 & 18.5 & 23.0 & 16.5 & 29.5 & 29.3 & 29.7 & 2,251 & 674 & 1,577 \\
\hline Married/living with a man & 69.7 & 75.2 & 67.8 & 1.3 & 2.2 & 1.0 & 6.2 & 4.8 & 6.7 & 22.8 & 17.9 & 24.5 & 185 & 48 & 136 \\
\hline \multicolumn{16}{|l|}{ Household wealth quintile } \\
\hline Lowest & 37.9 & 50.8 & 30.5 & 1.3 & 3.3 & 0.2 & 12.9 & 15.3 & 11.5 & 47.9 & 30.7 & 57.9 & 252 & 92 & 159 \\
\hline Second & 48.8 & 51.2 & 48.1 & 1.6 & 2.3 & 1.1 & 14.0 & 17.1 & 13.1 & 35.7 & 29.5 & 37.4 & 404 & 89 & 316 \\
\hline Middle & 50.1 & 42.3 & 52.6 & 1.5 & 1.1 & 1.7 & 19.2 & 23.9 & 17.7 & 29.2 & 32.7 & 28.0 & 539 & 131 & 408 \\
\hline Fourth & 58.0 & 46.3 & 61.9 & 0.9 & 1.5 & 0.7 & 16.3 & 20.7 & 14.8 & 24.9 & 31.5 & 22.7 & 606 & 151 & 455 \\
\hline Highest & 57.0 & 51.2 & 61.0 & 0.4 & 0.0 & 0.7 & 21.4 & 25.3 & 18.8 & 21.2 & 23.5 & 19.6 & 634 & 259 & 375 \\
\hline All respondents & 52.4 & 48.5 & 54.0 & 1.1 & 1.2 & 1.0 & 17.5 & 21.8 & 15.7 & 29.0 & 28.5 & 29.3 & 2,436 & 722 & 1,714 \\
\hline
\end{tabular}

Notes: aNever or formerly married 
Nandi County had the highest proportion of adolescent girls who intended to use a modern method in future, while Wajir had the lowest ( $89 \%$ and $2 \%$, respectively), while no non-users in Mandera County reported any intention to use a method in future (Table A4). Trans-Nzoia, Kericho, Kisii, Kitui, and Bungoma counties with highest proportions of adolescents girls intending to use a modern method in the future, while Marsabit, Garissa, West Pokot, and Lamu were counties with lowest proportions (Figure 5). One third or more adolescent girls in eight counties did not know the method they intend to use in future: Bomet (33\%), Meru (34\%), Kiambu (37\%), Taita Taveta (39\%), Kisumu (39\%), Kirinyaga (39\%), Nyamira (45\%), and Tharaka-Nithi (50\%; Table A4).

Figure 5: Counties with highest and lowest proportions of adolescent girls that intend to use modern methods of contraception in future

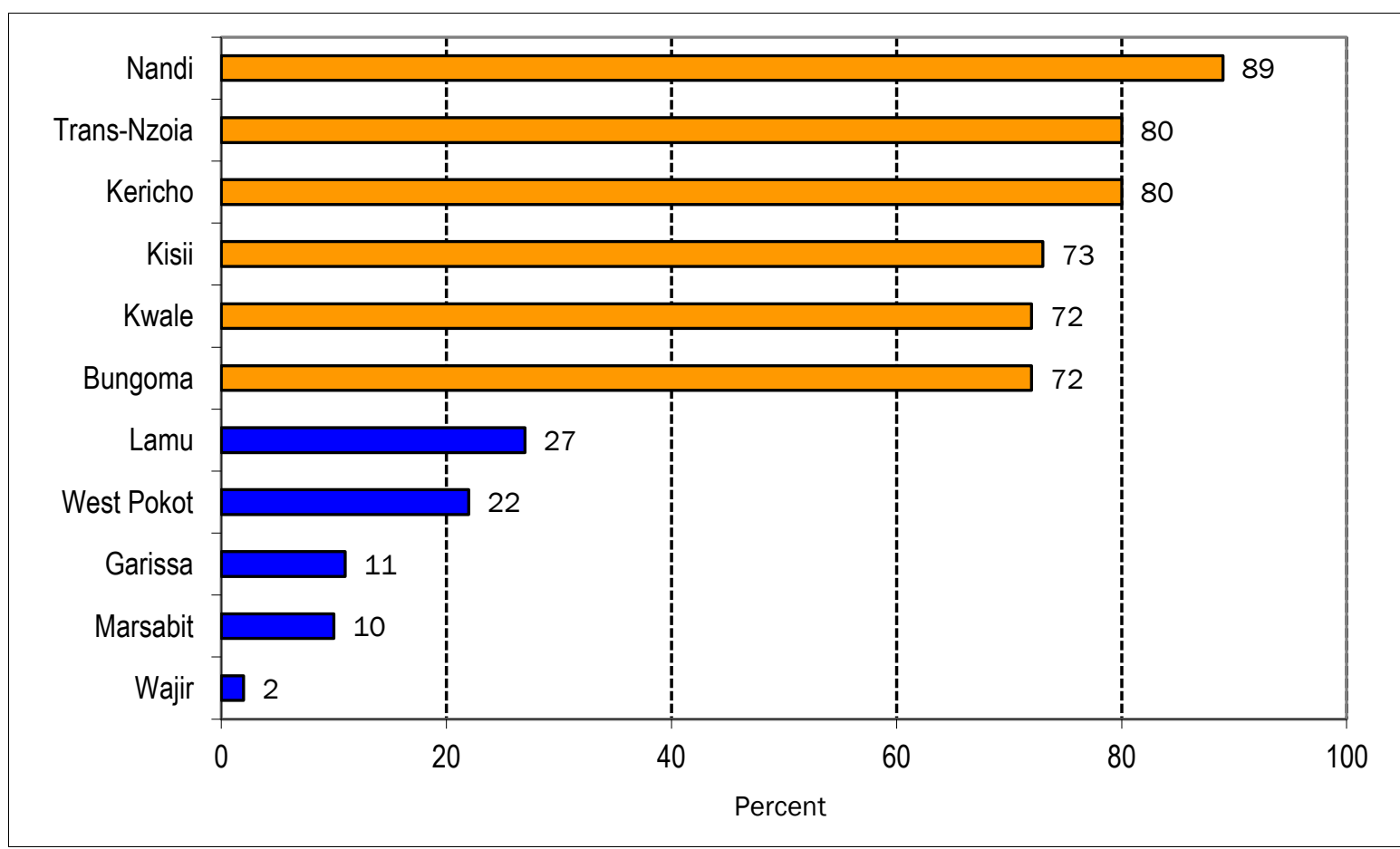

\section{Exposure to Family Planning Messages}

\section{Sources of Information for Girls}

Radio was adolescent girls' most common source of FP information, followed by print media (newspapers, magazines, informational materials), and television-at 66 percent, 49 percent, and 39 percent, respectivelyproviding FP messages in the preceding months (Table 10). The proportion of adolescent girls who heard FP messages from these sources was highest among those 18 to 19 years old and those with secondary and higher educations. The proportion also increased with higher household socio-economic status. The proportions of adolescent girls who heard about FP from health care workers, public forums, social media, phone or e-mail, or community leaders were much lower $(19 \%, 19 \%, 11 \%, 6 \%$ and $24 \%$, respectively).

A higher proportion of adolescent girls in urban than rural areas obtained FP information from any source (radio, television, print media, health care worker, public forums, social media, phone or e-mail, or community leaders; Table 10). Variations in the proportions that obtained information from radio, television, or print media, by age, education, and household wealth quintile, in both urban and rural areas, were similar to overall patterns. Television was the second most important source of FP information for urban adolescent girls, while print media was the second most important source for those in rural areas, and television third. 
Table 10: Sources of family planning information for adolescent girls 15 to 19 years old, by background

\begin{tabular}{|c|c|c|c|c|c|c|c|c|c|c|c|c|c|c|c|c|c|c|c|c|c|c|c|c|}
\hline \multirow[t]{2}{*}{ Characteristics } & \multicolumn{3}{|c|}{ Radio } & \multicolumn{3}{|c|}{ Television } & \multicolumn{3}{|c|}{ Print Media } & \multicolumn{3}{|c|}{ Health Provider } & \multicolumn{3}{|c|}{ Public Forums } & \multicolumn{3}{|c|}{ Social media } & \multicolumn{3}{|c|}{ Phone/email } & \multicolumn{3}{|c|}{ Community leaders } \\
\hline & \begin{tabular}{|l} 
All \\
sites
\end{tabular} & $\begin{array}{l}\text { Urban } \\
\text { areas }\end{array}$ & $\begin{array}{l}\text { Rural } \\
\text { areas }\end{array}$ & $\begin{array}{l}\text { All } \\
\text { sites }\end{array}$ & $\begin{array}{l}\text { Urban } \\
\text { areas }\end{array}$ & $\begin{array}{l}\text { Rural } \\
\text { areas }\end{array}$ & $\begin{array}{l}\text { All } \\
\text { sites }\end{array}$ & $\begin{array}{l}\text { Urban } \\
\text { areas }\end{array}$ & $\begin{array}{l}\text { Rural } \\
\text { areas }\end{array}$ & \begin{tabular}{|l|} 
All \\
sites
\end{tabular} & $\begin{array}{l}\text { Urban } \\
\text { areas }\end{array}$ & $\begin{array}{l}\text { Rural } \\
\text { areas }\end{array}$ & $\begin{array}{l}\text { All } \\
\text { sites }\end{array}$ & $\begin{array}{l}\text { Urban } \\
\text { areas }\end{array}$ & $\begin{array}{l}\text { Rural } \\
\text { areas }\end{array}$ & $\begin{array}{l}\text { All } \\
\text { sites }\end{array}$ & $\begin{array}{l}\text { Urban } \\
\text { areas }\end{array}$ & $\begin{array}{l}\text { Rural } \\
\text { areas }\end{array}$ & \begin{tabular}{|l} 
All \\
sites
\end{tabular} & $\begin{array}{l}\text { Urban } \\
\text { areas }\end{array}$ & $\begin{array}{l}\text { Rural } \\
\text { areas }\end{array}$ & $\begin{array}{l}\text { All } \\
\text { sites }\end{array}$ & $\begin{array}{l}\text { Urban } \\
\text { areas }\end{array}$ & $\begin{array}{l}\text { Rural } \\
\text { areas }\end{array}$ \\
\hline \multicolumn{25}{|l|}{ Age group (years) } \\
\hline $15-17$ & 60.7 & 68.4 & 57.8 & 33.5 & 62.1 & 23.0 & 44.2 & 57.0 & 39.4 & 12.7 & 17.2 & 11.3 & 15.2 & 22.7 & 12.4 & 6.9 & 15.3 & 3.8 & 4.2 & 7.7 & 2.9 & 20.8 & 28.1 & 18.1 \\
\hline $18-19$ & 74.1 & 74.4 & 73.9 & 47.0 & 69.9 & 33.1 & 57.2 & 66.5 & 51.5 & 26.6 & 28.7 & 25.6 & 26.3 & 30.5 & 23.8 & 18.0 & 25.6 & 13.3 & 7.6 & 9.7 & 6.4 & 29.0 & 27.3 & 30.0 \\
\hline \multicolumn{25}{|l|}{ Highest level of education } \\
\hline No schooling/primary & 54.3 & 62.5 & 52.0 & 22.4 & 46.3 & 15.8 & 34.0 & 42.5 & 31.6 & 17.0 & 22.9 & 15.5 & 13.9 & 21.8 & 11.7 & 2.7 & 4.9 & 2.1 & 1.8 & 3.1 & 1.4 & 18.1 & 23.1 & 16.7 \\
\hline Secondary and above & 77.2 & 75.9 & 78.0 & 54.8 & 76.1 & 40.5 & 64.2 & 71.5 & 59.2 & 20.4 & 23.2 & 18.9 & 24.9 & 28.8 & 22.4 & 19.5 & 28.2 & 13.6 & 9.2 & 11.6 & 7.6 & 29.7 & 30.2 & 29.3 \\
\hline \multicolumn{25}{|c|}{ Attended school at any time in 2014} \\
\hline No & 70.7 & 74.1 & 67.9 & 47.2 & 68.4 & 30.0 & 52.9 & 65.5 & 42.8 & 31.8 & 29.2 & 33.4 & 22.5 & 24.8 & 20.7 & 16.5 & 21.5 & 12.4 & 7.2 & 9.8 & 5.1 & 26.8 & 28.6 & 25.4 \\
\hline Yes & 63.6 & 69.1 & 61.8 & 34.9 & 63.5 & 25.4 & 47.4 & 57.8 & 44.0 & 10.6 & 14.9 & 9.5 & 18.2 & 27.8 & 15.1 & 8.8 & 19.1 & 5.4 & 4.8 & 7.8 & 3.8 & 22.8 & 27.4 & 21.3 \\
\hline \multicolumn{25}{|l|}{ Current marital status } \\
\hline Unmarrieda & 65.5 & 70.2 & 63.4 & 38.9 & 66.4 & 26.9 & 49.5 & 61.3 & 44.4 & 14.9 & 19.6 & 13.1 & 18.8 & 26.4 & 15.5 & 11.4 & 22.0 & 6.7 & 5.5 & 8.8 & 4.1 & 23.8 & 28.3 & 21.9 \\
\hline Married/living with a man & 68.3 & 77.6 & 62.9 & 37.2 & 61.0 & 23.2 & 45.9 & 62.1 & 36.4 & 39.3 & 38.1 & 39.9 & 24.6 & 25.8 & 24.0 & 9.1 & 7.3 & 10.2 & 5.4 & 7.5 & 4.1 & 24.6 & 24.3 & 24.8 \\
\hline \multicolumn{25}{|l|}{ Household wealth quintile } \\
\hline Lowest & 45.0 & 64.8 & 32.4 & 13.2 & 28.2 & 3.7 & 33.5 & 48.7 & 23.8 & 13.9 & 20.4 & 9.0 & 14.2 & 22.1 & 9.2 & 4.5 & 8.8 & 1.8 & 3.5 & 6.2 & 1.7 & 19.9 & 30.3 & 13.4 \\
\hline Second & 58.0 & 68.1 & 54.9 & 22.3 & 43.8 & 15.8 & 37.7 & 56.0 & 32.2 & 23.4 & 22.0 & 23.8 & 17.4 & 20.2 & 16.6 & 5.6 & 8.0 & 4.9 & 3.1 & 6.5 & 2.0 & 19.0 & 18.1 & 19.3 \\
\hline Middle & 65.0 & 70.2 & 63.1 & 29.8 & 57.0 & 20.3 & 42.0 & 53.3 & 38.0 & 20.1 & 32.6 & 16.2 & 19.8 & 25.3 & 17.8 & 7.9 & 15.5 & 5.2 & 4.2 & 4.4 & 4.2 & 21.1 & 26.8 & 19.1 \\
\hline Fourth & 70.4 & 71.5 & 70.0 & 42.4 & 81.4 & 27.5 & 53.4 & 64.6 & 49.0 & 22.4 & 29.1 & 20.0 & 20.1 & 31.8 & 15.6 & 14.6 & 27.5 & 9.6 & 6.8 & 10.8 & 5.2 & 27.0 & 23.8 & 28.2 \\
\hline Highest & 75.2 & 75.1 & 75.2 & 63.5 & 82.1 & 50.7 & 64.8 & 70.5 & 61.0 & 13.0 & 14.2 & 12.4 & 21.8 & 26.9 & 18.2 & 16.8 & 26.2 & 10.2 & 7.8 & 11.3 & 5.4 & 28.1 & 33.6 & 24.2 \\
\hline All respondents & 65.8 & 71.2 & 63.3 & 38.7 & 65.7 & 26.5 & 49.1 & 61.4 & 43.6 & 18.8 & 23.1 & 17.1 & 19.4 & 26.3 & 16.3 & 11.1 & 20.1 & 7.1 & 5.5 & 8.7 & 4.1 & 23.9 & 27.7 & 22.2 \\
\hline Number of respondents & 2,716 & 843 & 1,873 & 2,716 & 843 & 1,873 & 2,716 & 843 & 1,873 & 1,281 & 359 & 922 & 2,716 & 843 & 1,873 & 2,716 & 843 & 1,873 & 2,716 & 843 & 1,873 & 2,716 & 843 & 1,873 \\
\hline
\end{tabular}

Notes: $\quad$ aNever or formerly married. 
The proportion of adolescent girls who obtained FP information from radio ranged from two percent in Wajir to 88 percent in Taita Taveta (Table 11). Besides Wajir, counties with the lowest proportions of adolescent girls obtaining FP information from radio were Turkana (11\%), Garissa (12\%), and Samburu (13\%), while counties with the highest proportions were Nairobi $(84 \%)$, Bomet $(83 \%)$, Homa Bay $(82 \%)$, and Kericho $(81 \%)$. Five counties where television was the most common source of FP information for adolescent girls included Nairobi $(86 \%)$, Mombasa (79\%), Kiambu (72\%), Kajiado (69\%), and Kisumu (62\%). Television was least common as a source of FP information in Samburu (5\%), Wajir (6\%), Nyamira (8\%), West Pokot (9\%), and Garissa (10\%). Print media, on the other hand, was most common in Mombasa (88\%), Tharaka-Nithi (74\%), Kiambu (74\%), Nairobi (71\%), and Taita Taveta (71\%), and least common in West Pokot (3\%), Turkana (4\%), Samburu (5\%), Marsabit (6\%), Mandera (7\%), and Garissa (9\%; Table 11). Regardless of information source, there was a positive correlation between the proportion of adolescent girls accessing information and current use of a method, with counties where access to information was high generally being associated with greater use of a method (Figure A1). The association was, however, less strong for access to information from health care workers, social media, phone or e-mail, or community leaders, as evidenced by the less steep trend lines (Figure A1). 
Table 11: Distribution of sources of family planning information for adolescent girls 15 to 19 years old, by county

\begin{tabular}{|c|c|c|c|c|c|c|c|c|c|}
\hline County & Radio & Television & $\begin{array}{c}\text { Print } \\
\text { media }\end{array}$ & $\begin{array}{c}\text { Health } \\
\text { provider }\end{array}$ & $\begin{array}{l}\text { Public } \\
\text { forums }\end{array}$ & $\begin{array}{l}\text { Social } \\
\text { media }\end{array}$ & $\begin{array}{c}\text { Phone/ e- } \\
\text { mail }\end{array}$ & $\begin{array}{c}\text { Community } \\
\text { leaders }\end{array}$ & $\begin{array}{l}\text { Number } \\
\text { of cases }\end{array}$ \\
\hline Baringo & 58.0 & 31.5 & 42.6 & 11.9 & 23.0 & 8.1 & 3.1 & 44.9 & 37 \\
\hline Bomet & 82.8 & 15.0 & 43.4 & 11.7 & 11.0 & 4.5 & 0.7 & 10.6 & 68 \\
\hline Bungoma & 78.2 & 33.5 & 39.8 & 11.2 & 25.6 & 4.1 & 4.4 & 32.7 & 148 \\
\hline Busia & 64.8 & 24.9 & 43.3 & 17.6 & 14.9 & 3.0 & 2.9 & 18.8 & 75 \\
\hline Elgeyo Marakwet & 76.1 & 28.3 & 64.7 & 10.7 & 27.5 & 8.9 & 4.2 & 19.3 & 24 \\
\hline Embu & 42.3 & 18.5 & 41.6 & 5.5 & 5.8 & 3.5 & 1.3 & 13.8 & 42 \\
\hline Garissa & 12.4 & 10.5 & 8.8 & 5.4 & 1.2 & 8.8 & 0.0 & 0.0 & 31 \\
\hline Homa Bay & 81.9 & 19.3 & 43.7 & 15.1 & 27.3 & 16.2 & 9.6 & 24.8 & 80 \\
\hline Isiolo & 34.2 & 22.2 & 31.3 & 29.9 & 20.6 & 18.9 & 5.1 & 3.5 & 8 \\
\hline Kajiado & 68.2 & 68.9 & 61.2 & 15.6 & 20.6 & 34.9 & 7.3 & 30.7 & 44 \\
\hline Kakamega & 73.0 & 24.8 & 46.7 & 12.7 & 8.2 & 6.1 & 2.8 & 27.5 & 125 \\
\hline Kericho & 80.9 & 45.8 & 64.1 & 23.8 & 26.4 & 10.5 & 9.9 & 37.5 & 53 \\
\hline Kiambu & 71.5 & 71.9 & 73.7 & 26.8 & 20.7 & 22.7 & 3.8 & 41.7 & 127 \\
\hline Kilifi & 53.5 & 28.7 & 47.9 & 19.1 & 16.2 & 6.7 & 4.1 & 23.0 & 106 \\
\hline Kirinyaga & 50.4 & 35.8 & 29.6 & 24.4 & 12.4 & 11.5 & 1.6 & 5.0 & 25 \\
\hline Kisii & 75.6 & 36.5 & 25.9 & 33.1 & 11.9 & 11.8 & 0.4 & 22.0 & 90 \\
\hline Kisumu & 79.0 & 61.6 & 56.4 & 32.6 & 18.6 & 15.2 & 10.0 & 34.8 & 95 \\
\hline Kitui & 56.7 & 15.9 & 36.1 & 10.7 & 22.9 & 12.8 & 4.6 & 24.1 & 66 \\
\hline Kwale & 49.8 & 21.3 & 68.5 & 20.6 & 11.6 & 4.1 & 4.3 & 3.2 & 54 \\
\hline Laikipia & 33.6 & 23.3 & 20.5 & 19.6 & 8.4 & 2.9 & 0.0 & 10.4 & 30 \\
\hline Lamu & 57.2 & 25.8 & 29.7 & 7.2 & 17.2 & 0.8 & 3.4 & 13.0 & 11 \\
\hline Machakos & 68.4 & 24.7 & 41.9 & 20.6 & 23.8 & 8.5 & 2.1 & 17.1 & 64 \\
\hline Makueni & 55.0 & 32.5 & 43.7 & 11.7 & 30.7 & 8.3 & 4.3 & 25.8 & 77 \\
\hline Mandera & 35.8 & 22.8 & 7.3 & 29.2 & 2.0 & 2.0 & 2.0 & 0.0 & 18 \\
\hline Marsabit & 24.4 & 22.3 & 6.3 & 9.9 & 10.2 & 4.1 & 1.4 & 1.4 & 12 \\
\hline Meru & 27.6 & 27.3 & 35.1 & 20.9 & 4.4 & 3.3 & 1.2 & 6.6 & 94 \\
\hline Migori & 72.0 & 29.1 & 41.2 & 28.5 & 18.1 & 3.8 & 4.3 & 15.5 & 57 \\
\hline Mombasa & 60.3 & 79.4 & 88.3 & 42.0 & 31.0 & 16.4 & 14.9 & 21.4 & 48 \\
\hline Murang'a & 54.2 & 30.6 & 32.3 & 7.0 & 2.4 & 21.2 & 9.3 & 11.7 & 63 \\
\hline Nairobi & 84.3 & 86.2 & 70.6 & 26.3 & 40.9 & 22.8 & 13.7 & 36.8 & 217 \\
\hline Nakuru & 78.7 & 57.5 & 58.5 & 39.2 & 26.7 & 26.1 & 10.8 & 30.4 & 140 \\
\hline Nandi & 67.9 & 25.0 & 47.1 & 0.0 & 14.4 & 4.6 & 2.8 & 28.4 & 58 \\
\hline Narok & 66.5 & 14.2 & 53.5 & 30.5 & 20.0 & 2.6 & 1.8 & 42.0 & 49 \\
\hline Nyamira & 77.2 & 7.6 & 57.1 & 0.0 & 19.5 & 1.4 & 0.0 & 29.9 & 23 \\
\hline Nyandarua & 76.7 & 35.7 & 65.6 & 13.9 & 40.2 & 13.8 & 12.0 & 21.1 & 26 \\
\hline Nyeri & 60.5 & 47.1 & 58.7 & 8.3 & 21.8 & 13.0 & 12.0 & 31.8 & 50 \\
\hline Samburu & 13.4 & 5.4 & 4.5 & 16.2 & 0.4 & 0.0 & 0.0 & 0.0 & 9 \\
\hline Siaya & 78.2 & 23.2 & 44.3 & 26.3 & 13.0 & 7.6 & 0.6 & 2.8 & 62 \\
\hline Taita Taveta & 87.6 & 30.3 & 71.4 & 0.0 & 16.4 & 10.6 & 12.9 & 25.1 & 15 \\
\hline Tana River & 24.9 & 13.2 & 10.8 & 6.3 & 4.3 & 0.4 & 0.8 & 0.8 & 21 \\
\hline Tharaka-Nithi & 72.7 & 46.4 & 74.0 & 11.8 & 56.6 & 6.2 & 5.9 & 38.6 & 23 \\
\hline Trans-Nzoia & 73.0 & 26.3 & 59.9 & 3.8 & 13.1 & 6.5 & 3.8 & 26.1 & 80 \\
\hline Turkana & 11.3 & 11.6 & 4.0 & 9.4 & 1.6 & 5.6 & 0.0 & 0.0 & 21 \\
\hline Uasin Gishu & 62.2 & 44.0 & 45.5 & 13.9 & 20.0 & 7.1 & 2.3 & 18.5 & 68 \\
\hline Vihiga & 78.5 & 53.4 & 72.9 & 13.7 & 10.4 & 5.8 & 12.2 & 23.0 & 49 \\
\hline Wajir & 1.8 & 5.6 & 12.3 & 6.8 & 1.1 & 6.5 & 1.1 & 1.1 & 16 \\
\hline West Pokot & 16.9 & 8.7 & 2.7 & 19.7 & 0.0 & 0.0 & 0.0 & 0.0 & 15 \\
\hline
\end{tabular}




\section{Sources of Information for Boys}

Similar to girls, radio was the most common source of FP information for boys, followed by television and print media $(71 \%, 39 \%$ and $27 \%$, respectively; Table 12$)$. The proportion of adolescent boys who obtained information from these sources was highest among those ages 18 to 19 and those with secondary and higher educations; it also increased with higher household socio-economic status. In addition, a higher proportion of adolescent boys in urban than in rural areas obtained FP information from these sources. Variations by age and education in urban and rural areas were similar to overall patterns. The proportions that obtained information from the sources also increased by household socio-economic status among boys in rural areas, while in urban areas, there was wealth gradient in access to information from television but not in radio or print media. The proportion of boys who obtained information from health care workers was six times lower than that of girls, with no major variations between urban and rural areas (3\% and $2 \%$, respectively; Table 12$)$.

Table 12: Distribution of sources of family planning information for adolescent boys 15 to 19 years old, by background characteristics

\begin{tabular}{|c|c|c|c|c|c|c|c|c|c|c|c|c|}
\hline \multirow[t]{2}{*}{ Characteristics } & \multicolumn{3}{|c|}{ Radio } & \multicolumn{3}{|c|}{ Television } & \multicolumn{3}{|c|}{ Print Media } & \multicolumn{3}{|c|}{ Health Provider } \\
\hline & $\begin{array}{l}\text { All } \\
\text { sites }\end{array}$ & $\begin{array}{l}\text { Urban } \\
\text { areas }\end{array}$ & $\begin{array}{l}\text { Rural } \\
\text { areas }\end{array}$ & $\begin{array}{l}\text { All } \\
\text { sites }\end{array}$ & $\begin{array}{l}\text { Urban } \\
\text { areas }\end{array}$ & $\begin{array}{l}\text { Rural } \\
\text { areas }\end{array}$ & $\begin{array}{l}\text { All } \\
\text { sites }\end{array}$ & $\begin{array}{l}\text { Urban } \\
\text { areas }\end{array}$ & $\begin{array}{l}\text { Rural } \\
\text { areas }\end{array}$ & $\begin{array}{l}\text { All } \\
\text { sites }\end{array}$ & $\begin{array}{l}\text { Urban } \\
\text { areas }\end{array}$ & $\begin{array}{l}\text { Rural } \\
\text { areas }\end{array}$ \\
\hline \multicolumn{13}{|l|}{ Age group (years) } \\
\hline $15-17$ & 65.9 & 69.8 & 64.6 & 33.1 & 55.5 & 25.6 & 21.6 & 30.8 & 18.5 & 2.3 & 3.0 & 2.1 \\
\hline $18-19$ & 78.6 & 82.2 & 76.9 & 48.4 & 71.7 & 37.3 & 34.2 & 41.4 & 30.8 & 2.8 & 1.8 & 3.3 \\
\hline \multicolumn{13}{|l|}{ Highest level of education } \\
\hline No schooling/primary & 62.9 & 67.2 & 61.7 & 22.8 & 40.6 & 18.2 & 12.5 & 17.7 & 11.2 & 1.6 & 2.7 & 1.4 \\
\hline Secondary and above & 80.8 & 81.3 & 80.4 & 58.9 & 78.8 & 47.7 & 43.5 & 48.5 & 40.8 & 3.6 & 2.3 & 4.3 \\
\hline \multicolumn{13}{|c|}{ Attended school at any time in 2014} \\
\hline No & 70.2 & 76.6 & 66.5 & 42.1 & 60.8 & 31.5 & 25.9 & 32.4 & 22.2 & 1.6 & 1.7 & 1.4 \\
\hline Yes & 71.2 & 75.1 & 69.8 & 38.5 & 63.8 & 29.7 & 26.7 & 36.9 & 23.1 & 2.8 & 2.7 & 2.8 \\
\hline \multicolumn{13}{|l|}{ Current marital status } \\
\hline Unmarried $^{a}$ & 71.0 & 75.6 & 69.2 & 39.2 & 63.0 & 29.9 & 26.6 & 35.7 & 23.1 & 2.5 & 2.4 & 2.5 \\
\hline Married/living with a man & 67.5 & 23.8 & 75.2 & 43.2 & 44.5 & 42.9 & 22.7 & 10.0 & 24.9 & 5.9 & 0.0 & 7.0 \\
\hline \multicolumn{13}{|l|}{ Household wealth quintile } \\
\hline Lowest & 47.0 & 68.7 & 29.8 & 14.3 & 25.9 & 5.1 & 12.8 & 23.3 & 4.5 & 1.6 & 2.9 & 0.5 \\
\hline Second & 69.0 & 81.8 & 63.6 & 27.7 & 48.4 & 18.9 & 19.5 & 30.2 & 14.9 & 2.3 & 2.5 & 2.2 \\
\hline Middle & 70.8 & 71.3 & 70.6 & 31.1 & 64.7 & 19.9 & 26.0 & 44.3 & 19.9 & 2.5 & 1.5 & 2.8 \\
\hline Fourth & 78.2 & 81.8 & 77.1 & 45.7 & 81.5 & 34.6 & 29.1 & 36.9 & 26.7 & 2.8 & 3.6 & 2.6 \\
\hline Highest & 77.1 & 72.4 & 78.7 & 63.9 & 90.1 & 54.8 & 37.9 & 41.9 & 36.6 & 2.9 & 1.9 & 3.3 \\
\hline All respondents & 71.0 & 75.4 & 69.2 & 39.2 & 62.9 & 30.0 & 26.6 & 35.7 & 23.1 & 2.5 & 2.4 & 2.6 \\
\hline Number of respondents & 2,540 & 709 & 1,831 & 2,539 & 709 & 1,830 & 2,540 & 709 & 1,831 & 2,537 & 709 & 1,828 \\
\hline
\end{tabular}

Notes: aNever or formerly married. 


\section{Experiences of Sexual and Gender-Based Violence}

\section{Emotional Abuse}

About one fifth (19\%) of the sample of ever married adolescent girls asked about experiences of gender-based violence $(\mathrm{N}=111)$ reported emotional abused by their husbands or partners ( $16 \%$ in urban and $20 \%$ in rural areas; not shown). Emotional abuse entailed being humiliated, threatened with harm, insulted, or made to feel bad by the husband or partner. The proportion reporting emotional abuse was higher among those ages 18 to 19 than those 15 to 17 years old ( $21 \%$ and $11 \%$, respectively; $\mathrm{N}=30$ and $\mathrm{N}=81$, respectively; not shown). It was also nearly four times higher among those with primary or no schooling than among those with secondary and higher educations ( $23 \%$ and $6 \%$, respectively; $\mathrm{N}=85$ and $\mathrm{N}=26$, respectively; not shown).

\section{Sexual Abuse}

Less than 10 percent of adolescent girls asked about gender-based violence had experienced sexual abuse, being forced to have sexual intercourse or perform sexual acts against their wishes $(9 \%$ in urban and $5 \%$ in rural areas; Table 13). The proportion that had ever experienced sexual abuse was highest among those ages 18 to 19 , those with primary or no schooling, those who did not attend school at any time in 2014, ever married individuals, and those who had begun childbearing. These patterns were consistent in both urban and rural areas. There was no clear pattern in the experiences of sexual abuse by household wealth quintiles in urban areas, while in rural areas it was highest among adolescent girls from the poorest households. Only a small fraction (3\%) of adolescent boys asked about gender-based violence reported any sexual abuse (4\% in urban and $2 \%$ in rural areas; Table 13 ).

Table 13: Distribution of adolescents girls and boys 15 to 19 years old who had experienced sexual abuse, by background characteristics

\begin{tabular}{|c|c|c|c|c|c|c|}
\hline \multirow[b]{2}{*}{ Characteristics } & \multicolumn{2}{|c|}{ Urban } & \multicolumn{2}{|c|}{ Rural } & \multicolumn{2}{|c|}{ All sites } \\
\hline & $\begin{array}{c}\text { Female } \\
(\%)\end{array}$ & $\begin{array}{c}\text { Male } \\
(\%)\end{array}$ & $\begin{array}{c}\text { Female } \\
(\%)\end{array}$ & $\begin{array}{c}\text { Male } \\
(\%)\end{array}$ & $\begin{array}{c}\text { Female } \\
(\%)\end{array}$ & $\begin{array}{c}\text { Male } \\
(\%)\end{array}$ \\
\hline \multicolumn{7}{|l|}{ Age group (years) } \\
\hline $15-17$ & 3.8 & 4.2 & 5.1 & 2.4 & 4.8 & 2.8 \\
\hline $18-19$ & 17.0 & 3.4 & 6.1 & 2.1 & 9.6 & 2.5 \\
\hline \multicolumn{7}{|l|}{ Highest level of education } \\
\hline No schooling/primary & 17.1 & 2.0 & 7.5 & 2.9 & 9.7 & 2.7 \\
\hline Secondary and above & 4.3 & 5.2 & 3.2 & 1.3 & 3.6 & 2.7 \\
\hline \multicolumn{7}{|c|}{ Attended school at any time in 2014} \\
\hline No & 15.1 & 1.9 & 7.4 & 5.7 & 10.4 & 4.5 \\
\hline Yes & 4.6 & 4.5 & 4.9 & 1.2 & 4.8 & 2.0 \\
\hline \multicolumn{7}{|l|}{ Marital experience } \\
\hline Never married & 9.3 & 3.8 & 5.2 & 2.3 & 6.4 & 2.7 \\
\hline Ever marrieda & 9.9 & 0.0 & 6.8 & 0.0 & 8.0 & 0.0 \\
\hline \multicolumn{7}{|l|}{ Has begun childbearing } \\
\hline No & 8.6 & 3.8 & 5.3 & 2.2 & 6.2 & 2.7 \\
\hline Yes & 12.6 & 0.0 & 6.0 & 10.4 & 8.4 & 8.9 \\
\hline \multicolumn{7}{|l|}{ Household wealth quintile } \\
\hline Lowest & 9.6 & 7.2 & 7.4 & 0.0 & 8.3 & 2.9 \\
\hline Second & 13.3 & 2.0 & 4.5 & 0.9 & 6.2 & 1.2 \\
\hline Middle & 8.5 & 0.0 & 5.7 & 4.0 & 6.4 & 3.1 \\
\hline Fourth & 1.5 & 6.2 & 6.2 & 0.0 & 5.2 & 1.2 \\
\hline Highest & 12.5 & 4.2 & 4.2 & 5.4 & 7.4 & 5.0 \\
\hline All respondents & 9.4 & 3.8 & 5.4 & 2.3 & 6.5 & 2.7 \\
\hline Number of respondents & 280 & 247 & 729 & 703 & 1,009 & 950 \\
\hline
\end{tabular}

Notes: ${ }^{a}$ Formerly or currently married/living with a man/woman; Sexual abuse- being forced to have sexual intercourse or to perform sexual acts against wishes. 


\section{Physical Abuse}

Physical abuse was the most commonly reported form of gender-based violence among adolescents, with 71 percent of girls and 58 percent of boys reporting ever having been slapped, kicked, dragged, threatened, armtwisted, pushed, or choked (Table 14). The proportion of adolescent girls reporting experiences of physical abuse was highest among those 18 to 19 tears old, those with primary or no schooling, those who did not attend school at any time in 2014, ever married individuals, those who had begun childbearing, and those from the extreme ends of household wealth quintile distribution. These patterns were largely similar for boys, except for the distribution by childbearing experiences and household wealth quintiles. Adolescent boys who had no children and those from the extreme ends of the household wealth quintile distribution were the least likely to report experiencing physical abuse.

Table 14: Distribution of adolescent girls and boys 15 to 19 years old who had experienced physical abuse, by background characteristics

\begin{tabular}{|l|cc|cc|cc|}
\hline \multirow{2}{*}{ Characteristics } & \multicolumn{2}{|c|}{ Urban } & \multicolumn{2}{c|}{ Rural } & \multicolumn{2}{c|}{ All sites } \\
\cline { 2 - 7 } & $\begin{array}{c}\text { Female } \\
\text { (\%) }\end{array}$ & $\begin{array}{c}\text { Male } \\
(\%)\end{array}$ & $\begin{array}{c}\text { Female } \\
(\%)\end{array}$ & $\begin{array}{c}\text { Male } \\
(\%)\end{array}$ & $\begin{array}{c}\text { Female } \\
(\%)\end{array}$ & $\begin{array}{c}\text { Male } \\
(\%)\end{array}$ \\
\hline Age group (years) & & & & & & \\
15-17 & 70.0 & 47.5 & 69.3 & 59.6 & 69.5 & 56.8 \\
18-19 & 80.5 & 59.8 & 70.5 & 58.8 & 73.7 & 59.1 \\
\hline Highest level of education & & & & & & \\
\hline No schooling/primary & 73.6 & 48.0 & 71.4 & 61.9 & 71.9 & 59.2 \\
$\quad$ Secondary and above & 75.3 & 57.3 & 67.9 & 54.6 & 70.2 & 55.5 \\
\hline Attended school at any time in 2014 & & & & & & \\
\hline No & 75.2 & 50.8 & 74.3 & 72.9 & 74.6 & 66.3 \\
Yes & 75.1 & 54.1 & 68.5 & 55.2 & 70.0 & 54.9 \\
\hline Marital experience & & & & & & \\
\hline Never married & 73.2 & 52.8 & 67.8 & 59.3 & 69.3 & 57.6 \\
Ever marrieda & 82.0 & 100.0 & 87.3 & 57.9 & 85.3 & 67.3 \\
\hline Has begun childbearing & & & & & & \\
\hline No & 73.5 & 53.0 & 69.0 & 59.7 & 70.1 & 58.0 \\
$\quad$ Yes & 78.2 & 100.0 & 74.3 & 0.0 & 75.7 & 14.5 \\
\hline Household wealth quintile & & & & & & \\
\hline Lowest & 56.9 & 41.0 & 85.4 & 46.8 & 73.8 & 44.5 \\
Second & 70.8 & 49.8 & 67.7 & 67.6 & 68.3 & 63.6 \\
Middle & 80.8 & 58.6 & 65.6 & 55.9 & 69.2 & 56.5 \\
Fourth & 69.3 & 57.3 & 62.1 & 66.9 & 63.6 & 65.0 \\
Highest & 82.6 & 55.2 & 78.7 & 50.6 & 80.2 & 52.1 \\
\hline All respondents & 74.5 & 53.2 & 69.7 & 59.3 & 71.0 & 57.7 \\
\hline Number of respondents & 280 & 247 & 729 & 703 & 1,009 & 950 \\
\hline
\end{tabular}

Notes: aFormerly or currently married/living with a man/woman; Physical abuse- being slapped, kicked, dragged, threatened, armtwisted, pushed or choked.

The proportion of adolescent girls reporting experiences of physical abuse was higher in urban than rural areas (75\% and $70 \%$, respectively) while the proportion of boys reporting such abuse was higher in rural than in urban areas (59\% and 53\%, respectively; Table 14). There were also urban and rural differences in the proportions of adolescent girls and boys reporting experiences of physical abuse, by education and school attendance. The proportions of adolescent girls in urban areas reporting physical abuse were similar among those with secondary and higher as well as lower levels of education. The pattern was similar for school attendance in 2014. By contrast, in rural areas the proportion was highest among adolescent girls with primary or no schooling and those who did not attend school at any time in 2014. For boys in urban areas, the proportion was highest among those with secondary and higher educations and those who attended school at any time in 2014, while in rural areas it was lowest among those with these characteristics (Table 14). 


\section{Summary and Implications}

\section{Summary of Sexual and Reproductive Health Indicators}

Compared to boys, a lower proportion of adolescent girls interviewed in 2014 attended school at any one time during the year ( $68 \%$ and $78 \%$, respectively) while a higher proportion of girls had ever been married $(13 \%$ and $1 \%$, respectively). Although the proportion of adolescent girls and boys who attended school at any one time in 2014 was higher in rural areas, the proportion with secondary or higher educations was higher in urban areas. There were, however, no variations in the proportions of adolescent girls and boys who had ever been married, by type of place of residence (14\% and $13 \%$ of urban and rural adolescent girls, respectively, and $1 \%$ of urban and rural adolescent boys).

More than one third (37\%) of adolescent girls and 41 percent of adolescent boys had ever had sexual intercourse, with sexual activity higher among urban adolescents (41\% and $35 \%$ of urban and rural adolescent girls, and $42 \%$ and $40 \%$ of urban and rural adolescent boys, respectively). Sexual activity was also higher among older adolescents (18 to 19 years old), those who did not attend school at any time in 2014, and girls with primary or education or less. The proportion of adolescent girls that had ever had sexual intercourse ranged from 64 percent in West Pokot County to 15 percent in Nyandarua County.

Eighteen percent of adolescent girls ages 15 to 19 had begun childbearing (i.e. had ever given birth or were pregnant at the time of the survey). Adolescent childbearing was higher in rural than urban areas ( $19 \%$ and $17 \%$, respectively), among those 18 to 19 years old, those with primary education or no schooling, those who did not attend school at any time in 2014, ever married individuals, and those from households in the bottom two wealth quintiles, with the patterns consistent in both urban and rural areas. Adolescent childbearing ranged from 40 percent in Narok County to seven percent in Nyeri County.

More than one quarter $(29 \%)$ of adolescent girls who had begun childbearing reported ever experiencing an unintended pregnancy (i.e. a previous birth or current pregnancy that was either wanted later (28.8\%) or not at all $(0.2 \%))$, with the proportion higher in rural than in urban areas (30\% and $28 \%$, respectively), among those 15 to 17 years old, those with secondary and higher educations, those who attended school at any time in 2014, and never married individuals.

About one quarter (27\%) of adolescent girls and 44 percent of adolescent boys who had ever had sexual intercourse reported using any method of contraception at the time of the survey with a large proportion $(25 \%$ of girls and $43 \%$ of boys) using modern methods. Contraceptive use was higher among urban than rural adolescents, those aged 18 to 19 , and those who did not attend school at any time in 2014. Use of modern methods among sexually active adolescent girls ranged from 50 percent in Kiambu County to none in Garissa and Mandera counties. The most commonly used methods by sexually active adolescent girls were injectables $(48 \%)$, condoms $(26 \%)$, and implants $(12 \%)$, although use of injectables was higher in rural than in urban areas (53\% and $42 \%$, respectively) while use of condoms, implants and pills was higher in urban areas.

Most adolescent girls using contraception (47\%) obtained their method from public health facilities, while 25 percent obtained them from private health facilities and 20 percent obtained them from other sources including shops, mobile clinics, community-based distributors, and friends or relatives. Public facilities were major sources for those 18 to 19 years old, those with primary education or no schooling, those who did not attend school at any time in 2014, married individuals, and those from the poorest households, while private facilities were major sources for those 15 to 17 years old, those with secondary and higher educations, and those from the richest households. A higher proportion of those in urban areas obtained the methods from private than public facilities 
( $40 \%$ and $34 \%$, respectively) while in rural areas a higher proportion obtained methods from public rather than private facilities ( $56 \%$ and $14 \%$, respectively).

Unlike adolescent girls, only 32 percent of adolescent boys using condoms obtained them from a health facility (public or private), with $66 \%$ obtaining them from other sources.

Unmet need for contraception was higher among married adolescent girls (23\%) than among all married women $(18 \%)$, although it was more for spacing $(22 \%)$ than limiting births (1\%), while for all married women it was equally for spacing and limiting. In addition, unmet need was higher among those aged 18 to 19 (25\%), those with primary education or no schooling (24\%), and those from the poorest households (32\%). It was also higher in rural than in urban areas ( $29 \%$ and $14 \%$ ) with variations by age, education, and household wealth index. In urban areas, it was higher among those 15 to 17 years old, those with primary education or no schooling, and those from the poorest households, while in rural areas it was higher among those 18 to 19 years old, those with secondary and higher educations, and those from households in the extreme and middle quintiles.

Most $(71 \%)$ adolescent girls not currently using contraception intend to use a method in the future, with the majority (52\%) intending to use a modern method while a substantial proportion (18\%) did not know the method they intend to use. The proportion that did not know the method they intend to use was higher among those 15 to 17 years old, those who attended school at any time in 2014, and unmarried individuals. The proportions of nonusers that intend to use a method in future were similar in both urban and rural areas $(72 \%$ and $71 \%$, respectively) although the proportion that did not know the method they intend to use was higher in urban than rural areas (22\% and $16 \%$, respectively). The proportion of adolescent girls intending to use a modern method in the future ranged from 89 percent in Nandi County to two percent in Wajir, with no non-users in Mandera County reporting any intention to use a method in the future.

Most adolescent girls obtained family planning information from radio (66\%), then print media, including newspapers, magazines, or informational materials (49\%), and then television (39\%). The proportions that heard about family planning from health care workers, public forums, social media, phone or e-mail, or community leaders were much lower $(19 \%, 19 \%, 11 \%, 6 \%$ and $24 \%$, respectively). A higher proportion of adolescent girls in urban than in rural areas obtained family planning information from multiple sources, and among those the proportion that obtained family planning information from radio ranged from two percent in Wajir to 88 percent in Taita Taveta, three percent in West Pokot to 88 percent in Mombasa from print media, and five percent in Samburu to 86 percent in Nairobi from television. Regardless of information source, there was a positive correlation between the proportion of adolescent girls accessing information and current use of a method, with counties where access to information was high generally associated with greater use of a method. Similar to girls, radio was the most common source of family planning information for boys, followed by television and print media $(71 \%, 39 \%$ and $27 \%$, respectively).

About one fifth (19\%) of ever married adolescent girls who were asked about experiences of gender-based violence reported emotionally abuse (humiliated, threatened with harm, insulted or made to feel bad) by their husbands or partners (16\% in urban and $20 \%$ in rural areas). Less than 10 percent of adolescent girls asked about gender-based violence had experienced sexual abuse, being forced to have sexual intercourse or perform sexual acts against their wishes ( $9 \%$ in urban and $5 \%$ in rural areas). Only a small fraction (3\%) of adolescent boys asked about gender-based violence reported sexual abuse (4\% in urban and $2 \%$ in rural areas). Physical abuse was the most common form of gender-based violence among adolescents, with 71 percent of girls and 58 percent of boys indicating that they had ever been slapped, kicked, dragged, threatened, arm-twisted, pushed, or choked. The proportion of adolescent girls reporting experiences of physical abuse was higher in urban than in rural areas (75\% and $70 \%$, respectively), while the proportion of boys reporting such abuse was higher in rural than in urban areas (59\% and $53 \%$, respectively). 


\section{Implications}

- Low use of contraception among sexually active adolescents coupled with high unmet need among married adolescent girls, high intentions to use a method in future among non-users, and lack of knowledge of methods to use among a substantial proportion of those who intend to use contraception suggest the need for concerted efforts to reach this segment of the population with targeted information and services.

- Differences in certain SRH indicators by socio-demographic characteristics suggest the need to make contraceptive information and services responsive to the needs of various groups of adolescents, especially those hard to reach including the poor, those with low levels of education, and those in rural or remote areas.

- Variations in the importance of various sources of contraceptive information and services suggest that different contexts require different strategies. The public sector is more important in rural areas than the private sector is, a mix of the public and private sector approaches might work in urban areas while in both contexts radio would be the most common medium for reaching adolescents with contraceptive information.

- Although subject to under-reporting, the fact that a section of ever married adolescent girls reported emotional abuse by their spouses or partners, and that a section of adolescents reported sexual abuse, indicates that sexual and reproductive health interventions should consider addressing intimate partner violence as well as sexual abuse among this segment of the population. 


\section{Limitations of Analysis}

One limitation of the analysis is that it relies on existing cross-sectional data. Thus, although there are notable variations in some of the SRH indicators by certain characteristics of the adolescents, it is not possible to make causal inferences or provide explanations for the observed patterns. Small sample sizes might also affect some of the estimates at the county level and in some instances could not allow for analysis at such level. In addition, indicators of sexual and gender-based violence may be biased downwards because of under-reporting due to stigma associated with the experiences. 


\section{References}

Abou-Zahr, C.L. and Wardlaw, T.M. 2003. Antenatal care in developing countries: Promises, achievements and missed opportunities: An analysis of trends, levels and differentials, 1990-2001. Geneva: WHO and UNICEF.

Alam, Nurul. 2000. "Teenage motherhood and infant mortality in Bangladesh: Maternal age-dependent effect of parity one." Journal of Biosocial Science 32(2):229-236.

Chen, Xi-Kuan, Shi Wu Wen, Nathalie Fleming, Kitaw Demissie, George G Rhoads, and Mark Walker. 2007. "Teenage pregnancy and adverse birth outcomes: A large population based retrospective cohort study." International Journal of Epidemiology 36(2):368-372.

Conde-Agudelo, Agustin, José M. Belizán, and Cristina Lammers. 2005. "Maternal-perinatal morbidity and mortality associated with adolescent pregnancy in Latin America: Cross-sectional study." American Journal of Obstetrics and Gynecology 192(2):342-349.

Fotso, Jean-Christophe. 2006. "Child health inequities in developing countries: Differences across urban and rural areas." International Journal for Equity in Health 5(1):9.

Jolly, M.C., N. Sebire, J. Harris, S. Robinson, and L. Regan. 2000. "Obstetric risks of pregnancy in women less than 18 years old." Obstetrics and Gynecology 96(6):962-966.

Katz, K. and C. Naré. 2002. "Reproductive health knowledge and use of services among young adults in Dakar, Senegal." Journal of Biosocial Science 34(2):215-231.

KNBS (Kenya National Bureau of Statistics), Ministry of Health (MOH), National AIDS Control Council (NACC), Kenya Medical Research Institute (KEMRI), and National Council for Population and Development (NCPD). (2015). Kenya Demographic and Health Survey 2014: Key Indicators. Nairobi: KNBS, $\mathrm{MOH}, \mathrm{NACC}, \mathrm{KEMRI}$ and NCPD.

Magadi, Monica, Alfred Agwanda, Francis Obare and Negussie Taffa. 2007. "Size of Newborn and Caesarean Section Deliveries among Teenagers in sub-Saharan Africa: Evidence from DHS." Journal of Biosocial Science 39(2):175-187.

Magadi, Monica. 2006. "Poor pregnancy outcomes among adolescents in South Nyanza region of Kenya." African Journal of Reproductive Health 10(1):26-38.

Magadi, Monica Akinyi, Eliya Msiyaphazi Zulu, and Martin Brockerhoff. 2003. "The inequality of maternal health care in urban sub-Saharan Africa in the 1990s." Population Studies 57(3):347-366.

Reynolds, Heidi W., Emelita L. Wong, and Heidi Tucker. 2006. "Adolescents' use of maternal and child health services in developing countries." International Family Planning Perspectives 32(1):6-16.

UN/DPI (United Nations Department of Public Information). 1995. ICPD '94: Summary of the Programme of Action. Proceedings of the 1994 International Conference on Population and Development, Cairo. New York: UN/DPI.

UNFPA (United Nations Fund for Population Activities). 2007. UNFPA framework for action on adolescents and youth. New York: UNFPA.

UNICEF (United Nations Children's Fund), Joint United Nations Programme on HIVIAIDS (UNAIDS), and World Health Organization (WHO). 2002. Young people and HIVIAIDS: Opportunity in crisis. New York: UNICEF, UNAIDS and UNFPA.

United Nations. 1996. Report of the Fourth World Conference on Women. New York: United Nations. 
Warenius, L.U., E.A. Faxelid, P.N. Chishimba, J.O. Musandu, A.A. Ong'any, and E.B. Nissen. 2006. "Nursemidwives' attitudes towards adolescent sexual and reproductive health needs in Kenya and Zambia." Reproductive Health Matters 14(27):119-128.

Wood, K and R. Jewkes. 2006. "Blood blockages and scolding nurses: Barriers to adolescent contraceptive use in South Africa." Reproductive Health Matters 14(27):109-118.

WHO (World Health Organization). 2005. Integrating sexual health interventions into reproductive health services: Programme experience from developing countries. Geneva: World Health Organization.

Zere, Eyob, Matshidiso Moeti, Joses Kirigia, Takondwa Mwase, and Edward Kataika. 2007. "Equity in health and health care in Malawi: Analysis of trends." BMC Public Health 7:78. 


\section{Appendices}

Table A1: Distribution of adolescent girls 15 to 19 years old who had ever had sexual intercourse, by county and household wealth index

\begin{tabular}{|c|c|c|c|c|}
\hline \multirow{2}{*}{ County } & \multicolumn{2}{|c|}{ All adolescent girls } & \multicolumn{2}{|c|}{$\begin{array}{l}\text { Adolescent girls from bottom three wealth } \\
\text { quintiles }\end{array}$} \\
\hline & Percent & Number of cases & Percent & Number of cases \\
\hline Baringo & 43.1 & 83 & 48.3 & 57 \\
\hline Bomet & 46.5 & 129 & 46.6 & 83 \\
\hline Bungoma & 30.9 & 319 & 28.5 & 199 \\
\hline Busia & 39.6 & 131 & 40.6 & 78 \\
\hline Elgeyo Marakwet & 33.4 & 51 & 39.6 & 31 \\
\hline Embu & 16.1 & 91 & 16.4 & 73 \\
\hline Garissa & 19.8 & 67 & 27.3 & 31 \\
\hline Homa Bay & 53.6 & 177 & 56.1 & 110 \\
\hline Isiolo & 32.0 & 18 & 33.7 & 8 \\
\hline Kajiado & 42.7 & 106 & 59.9 & 54 \\
\hline Kakamega & 36.6 & 242 & 39.9 & 151 \\
\hline Kericho & 48.8 & 91 & 52.0 & 61 \\
\hline Kiambu & 39.4 & 142 & 34.7 & 139 \\
\hline Kilifi & 33.0 & 152 & 34.0 & 193 \\
\hline Kirinyaga & 25.3 & 54 & 31.6 & 34 \\
\hline Kisii & 37.7 & 191 & 43.5 & 106 \\
\hline Kisumu & 40.0 & 179 & 44.3 & 85 \\
\hline Kitui & 27.1 & 169 & 21.5 & 114 \\
\hline Kwale & 36.3 & 132 & 40.4 & 90 \\
\hline Laikipia & 29.7 & 65 & 26.3 & 50 \\
\hline Lamu & 28.8 & 20 & 28.8 & 16 \\
\hline Machakos & 29.8 & 143 & 20.7 & 93 \\
\hline Makueni & 27.0 & 168 & 26.2 & 98 \\
\hline Mandera & 24.2 & 36 & 40.5 & 13 \\
\hline Marsabit & 37.9 & 25 & 31.3 & 12 \\
\hline Meru & 39.9 & 185 & 44.6 & 138 \\
\hline Migori & 60.9 & 140 & 59.5 & 90 \\
\hline Mombasa & 35.3 & 123 & 48.3 & 60 \\
\hline Murang'a & 20.0 & 137 & 20.6 & 86 \\
\hline Nairobi & 46.2 & 467 & 53.0 & 216 \\
\hline Nakuru & 35.9 & 295 & 39.3 & 188 \\
\hline Nandi & 34.1 & 133 & 38.9 & 87 \\
\hline Narok & 51.8 & 107 & 52.7 & 81 \\
\hline Nyamira & 46.7 & 58 & 47.1 & 35 \\
\hline Nyandarua & 14.9 & 67 & 20.7 & 45 \\
\hline Nyeri & 18.9 & 101 & 18.7 & 55 \\
\hline Samburu & 56.0 & 21 & 61.2 & 12 \\
\hline Siaya & 37.8 & 130 & 31.4 & 86 \\
\hline Taita Taveta & 24.9 & 36 & 21.2 & 22 \\
\hline Tana River & 39.4 & 41 & 36.2 & 28 \\
\hline Tharaka-Nithi & 44.1 & 50 & 40.7 & 31 \\
\hline Trans-Nzoia & 40.2 & 185 & 44.6 & 137 \\
\hline Turkana & 45.7 & 51 & 35.6 & 24 \\
\hline Uasin Gishu & 44.7 & 137 & 41.6 & 87 \\
\hline Vihiga & 24.6 & 98 & 24.3 & 47 \\
\hline Wajir & 25.4 & 41 & 26.4 & 23 \\
\hline West Pokot & 63.5 & 38 & 50.9 & 21 \\
\hline
\end{tabular}


Table A2: Distribution of adolescent girls 15 to 19 years old who had begun childbearing, by county and household wealth index

\begin{tabular}{|c|c|c|c|c|}
\hline \multirow{2}{*}{ County } & \multicolumn{2}{|c|}{ All adolescent girls } & \multicolumn{2}{|c|}{$\begin{array}{l}\text { Adolescent girls from bottom three } \\
\text { wealth quintiles }\end{array}$} \\
\hline & Percent & Number of cases & Percent & Number of cases \\
\hline Baringo & 13.2 & 83 & 13.5 & 57 \\
\hline Bomet & 24.0 & 129 & 26.5 & 83 \\
\hline Bungoma & 14.4 & 319 & 11.7 & 199 \\
\hline Busia & 20.8 & 131 & 20.6 & 78 \\
\hline Elgeyo Marakwet & 8.7 & 51 & 9.5 & 31 \\
\hline Embu & 8.0 & 91 & 10.0 & 73 \\
\hline Garissa & 10.2 & 67 & 13.2 & 31 \\
\hline Homa Bay & 33.3 & 177 & 33.2 & 110 \\
\hline Isiolo & 18.9 & 18 & 10.9 & 8 \\
\hline Kajiado & 20.2 & 106 & 36.2 & 54 \\
\hline Kakamega & 19.4 & 242 & 26.9 & 151 \\
\hline Kericho & 20.5 & 91 & 26.5 & 61 \\
\hline Kiambu & 14.1 & 142 & 13.4 & 139 \\
\hline Kilifi & 21.8 & 152 & 24.4 & 193 \\
\hline Kirinyaga & 11.3 & 54 & 15.6 & 34 \\
\hline Kisii & 18.4 & 191 & 21.5 & 106 \\
\hline Kisumu & 15.4 & 179 & 19.6 & 85 \\
\hline Kitui & 14.8 & 169 & 13.3 & 114 \\
\hline Kwale & 24.2 & 132 & 30.0 & 90 \\
\hline Laikipia & 18.7 & 65 & 20.3 & 50 \\
\hline Lamu & 10.0 & 20 & 11.9 & 16 \\
\hline Machakos & 14.0 & 143 & 11.3 & 93 \\
\hline Makueni & 11.1 & 168 & 12.3 & 98 \\
\hline Mandera & 10.1 & 36 & 15.5 & 13 \\
\hline Marsabit & 16.6 & 25 & 20.0 & 12 \\
\hline Meru & 19.9 & 185 & 22.8 & 138 \\
\hline Migori & 24.3 & 140 & 25.0 & 90 \\
\hline Mombasa & 16.6 & 123 & 29.1 & 60 \\
\hline Murang'a & 6.3 & 137 & 8.1 & 86 \\
\hline Nairobi & 17.4 & 467 & 25.4 & 216 \\
\hline Nakuru & 18.4 & 295 & 23.9 & 188 \\
\hline Nandi & 15.6 & 133 & 20.0 & 87 \\
\hline Narok & 40.4 & 107 & 45.8 & 81 \\
\hline Nyamira & 27.8 & 58 & 28.8 & 35 \\
\hline Nyandarua & 9.7 & 67 & 14.4 & 45 \\
\hline Nyeri & 6.9 & 101 & 9.8 & 55 \\
\hline Samburu & 25.7 & 21 & 22.3 & 12 \\
\hline Siaya & 17.2 & 130 & 15.1 & 86 \\
\hline Taita Taveta & 13.4 & 36 & 16.5 & 22 \\
\hline Tana River & 28.2 & 41 & 27.2 & 28 \\
\hline Tharaka-Nithi & 13.7 & 50 & 12.9 & 31 \\
\hline Trans-Nzoia & 23.3 & 185 & 27.5 & 137 \\
\hline Turkana & 20.2 & 51 & 15.1 & 24 \\
\hline Uasin Gishu & 22.2 & 137 & 28.1 & 87 \\
\hline Vihiga & 12.7 & 98 & 12.4 & 47 \\
\hline Wajir & 17.4 & 41 & 13.2 & 23 \\
\hline West Pokot & 28.6 & 38 & 26.6 & 21 \\
\hline
\end{tabular}


Table A3: Distribution of adolescent girls 15 to 19 years old using contraception, among those who had ever had sexual intercourse, by county and type of method

\begin{tabular}{|c|c|c|c|}
\hline County & $\begin{array}{l}\text { Any method } \\
(\%)\end{array}$ & $\begin{array}{l}\text { Modern methods } \\
(\%)\end{array}$ & $\begin{array}{c}\text { Number of } \\
\text { cases }\end{array}$ \\
\hline Baringo & 14.4 & 11.9 & 36 \\
\hline Bomet & 12.9 & 9.7 & 60 \\
\hline Bungoma & 22.9 & 22.9 & 98 \\
\hline Busia & 17.0 & 17.0 & 52 \\
\hline Elgeyo Marakwet & 30.2 & 21.8 & 17 \\
\hline Embu & 17.5 & 17.5 & 15 \\
\hline Garissa & 0.0 & 0.0 & 13 \\
\hline Homa Bay & 35.3 & 34.1 & 95 \\
\hline Isiolo & 22.1 & 20.6 & 6 \\
\hline Kajiado & 16.2 & 13.8 & 45 \\
\hline Kakamega & 15.5 & 15.5 & 89 \\
\hline Kericho & 28.4 & 28.4 & 44 \\
\hline Kiambu & 49.6 & 49.6 & 95 \\
\hline Kilifi & 18.8 & 18.8 & 83 \\
\hline Kirinyaga & 45.0 & 45.0 & 14 \\
\hline Kisii & 39.4 & 39.4 & 72 \\
\hline Kisumu & 23.3 & 23.3 & 71 \\
\hline Kitui & 25.3 & 25.3 & 46 \\
\hline Kwale & 32.1 & 32.1 & 48 \\
\hline Laikipia & 13.8 & 13.8 & 19 \\
\hline Lamu & 16.8 & 16.8 & 6 \\
\hline Machakos & 50.6 & 42.9 & 43 \\
\hline Makueni & 46.6 & 34.7 & 45 \\
\hline Mandera & 0.0 & 0.0 & 9 \\
\hline Marsabit & 8.4 & 5.3 & 10 \\
\hline Meru & 34.8 & 34.8 & 74 \\
\hline Migori & 17.4 & 15.2 & 85 \\
\hline Mombasa & 51.8 & 41.5 & 44 \\
\hline Murang'a & 11.2 & 6.8 & 27 \\
\hline Nairobi & 36.2 & 34.4 & 216 \\
\hline Nakuru & 16.2 & 13.9 & 106 \\
\hline Nandi & 21.4 & 20.6 & 45 \\
\hline Narok & 20.1 & 8.9 & 56 \\
\hline Nyamira & 30.0 & 28.9 & 27 \\
\hline Nyandarua & 13.1 & 13.1 & 10 \\
\hline Nyeri & 19.5 & 19.5 & 19 \\
\hline Samburu & 10.7 & 10.7 & 12 \\
\hline Siaya & 22.9 & 22.0 & 49 \\
\hline Taita Taveta & 28.4 & 28.4 & 9 \\
\hline Tana River & 23.8 & 19.7 & 16 \\
\hline Tharaka-Nithi & 26.3 & 26.3 & 22 \\
\hline Trans-Nzoia & 47.4 & 35.3 & 74 \\
\hline Turkana & 8.2 & 8.2 & 23 \\
\hline Uasin Gishu & 27.8 & 26.5 & 61 \\
\hline Vihiga & 14.3 & 14.3 & 24 \\
\hline Wajir & 3.4 & 3.4 & 10 \\
\hline West Pokot & 4.0 & 4.0 & 24 \\
\hline
\end{tabular}


Table A4: Distribution of adolescent girls 15 to 19 years not currently using contraception who intend to use a method in future, by county and type of method

\begin{tabular}{|c|c|c|c|c|c|}
\hline County & $\begin{array}{l}\text { Modern } \\
\text { method }\end{array}$ & $\begin{array}{c}\text { Traditional } \\
\text { method }\end{array}$ & $\begin{array}{l}\text { Don't know } \\
\text { method }\end{array}$ & $\begin{array}{l}\text { Does not } \\
\text { intend to use }\end{array}$ & $\begin{array}{l}\text { Number } \\
\text { of cases }\end{array}$ \\
\hline Baringo & 59.1 & 1.8 & 7.8 & 31.4 & 34 \\
\hline Bomet & 36.0 & 1.0 & 33.4 & 29.6 & 66 \\
\hline Bungoma & 71.7 & 0.0 & 10.9 & 17.4 & 133 \\
\hline Busia & 53.6 & 1.8 & 10.8 & 33.8 & 68 \\
\hline Elgeyo Marakwet & 49.9 & 1.0 & 15.5 & 34.5 & 23 \\
\hline Embu & 51.7 & 0.0 & 18.2 & 30.2 & 42 \\
\hline Garissa & 10.7 & 0.0 & 0.0 & 89.3 & 31 \\
\hline Homa Bay & 60.6 & 1.0 & 1.0 & 38.4 & 65 \\
\hline Isiolo & 28.5 & 0.0 & 11.4 & 60.1 & 8 \\
\hline Kajiado & 49.3 & 5.4 & 7.3 & 37.9 & 42 \\
\hline Kakamega & 45.0 & 0.0 & 23.1 & 31.9 & 117 \\
\hline Kericho & 79.7 & 8.0 & 0.0 & 12.3 & 48 \\
\hline Kiambu & 38.3 & 0.0 & 36.7 & 25.0 & 99 \\
\hline Kilifi & 38.7 & 0.0 & 14.8 & 46.5 & 101 \\
\hline Kirinyaga & 32.7 & 0.0 & 39.1 & 28.2 & 21 \\
\hline Kisii & 72.6 & 1.3 & 11.9 & 14.2 & 74 \\
\hline Kisumu & 42.7 & 0.0 & 38.9 & 18.5 & 83 \\
\hline Kitui & 32.2 & 1.6 & 24.0 & 42.2 & 62 \\
\hline Kwale & 71.9 & 0.0 & 0.0 & 28.1 & 49 \\
\hline Laikipia & 60.2 & 3.4 & 12.9 & 23.6 & 28 \\
\hline Lamu & 27.0 & 2.7 & 16.0 & 54.3 & 11 \\
\hline Machakos & 65.2 & 0.0 & 11.4 & 23.4 & 55 \\
\hline Makueni & 43.3 & 6.4 & 30.8 & 19.4 & 74 \\
\hline Mandera & 0.0 & 0.0 & 0.0 & 100.0 & 18 \\
\hline Marsabit & 9.7 & 2.0 & 0.0 & 88.3 & 12 \\
\hline Meru & 54.9 & 0.7 & 33.7 & 10.7 & 83 \\
\hline Migori & 35.0 & 3.7 & 6.4 & 55.0 & 51 \\
\hline Mombasa & 61.9 & 0.0 & 8.2 & 29.9 & 38 \\
\hline Murang'a & 42.3 & 4.6 & 26.5 & 26.7 & 62 \\
\hline Nairobi & 56.2 & 0.0 & 26.3 & 17.5 & 171 \\
\hline Nakuru & 69.0 & 0.0 & 10.8 & 20.2 & 131 \\
\hline Nandi & 89.2 & 0.0 & 1.1 & 9.6 & 54 \\
\hline Narok & 38.9 & 0.8 & 30.9 & 29.5 & 45 \\
\hline Nyamira & 35.8 & 0.0 & 45.1 & 19.1 & 20 \\
\hline Nyandarua & 51.7 & 3.1 & 19.5 & 25.8 & 25 \\
\hline Nyeri & 47.0 & 0.0 & 26.7 & 26.4 & 47 \\
\hline Samburu & 38.7 & 0.0 & 1.3 & 60.0 & 8 \\
\hline Siaya & 63.9 & 1.6 & 6.9 & 27.6 & 56 \\
\hline Taita Taveta & 33.1 & 0.0 & 38.5 & 28.4 & 15 \\
\hline Tana River & 34.3 & 0.0 & 2.8 & 62.9 & 20 \\
\hline Tharaka-Nithi & 34.2 & 0.0 & 49.7 & 16.1 & 21 \\
\hline Trans-Nzoia & 80.0 & 0.0 & 10.2 & 9.9 & 69 \\
\hline Turkana & 31.4 & 0.0 & 3.4 & 65.2 & 20 \\
\hline Uasin Gishu & 61.3 & 1.4 & 6.8 & 30.5 & 58 \\
\hline Vihiga & 58.1 & 0.0 & 11.6 & 30.3 & 48 \\
\hline Wajir & 2.3 & 0.0 & 0.0 & 97.7 & 16 \\
\hline West Pokot & 22.1 & 0.0 & 0.0 & 77.9 & 14 \\
\hline
\end{tabular}


Figure A1: County correlations between access to family planning information from specific sources and current use of contraception among adolescent girls 15 to 19 years old
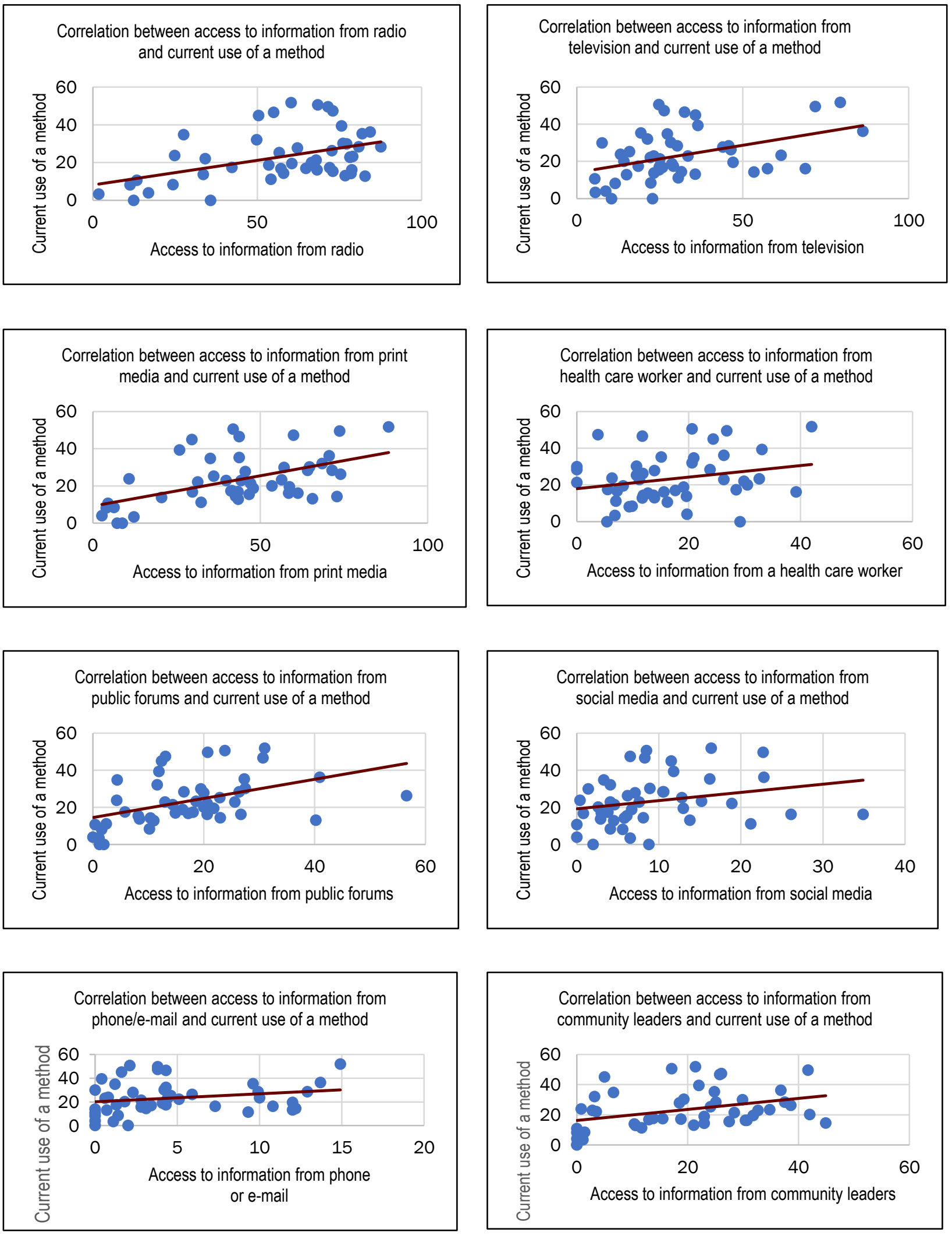